\title{
Methods and challenges for the seismic assessment of historic masonry structures
}

\author{
Gianmarco de Felice $^{1, a, *}$, Stefano De Santis ${ }^{1, b}$,Paulo B. Lourenço ${ }^{2, c}$ and Nuno Mendes ${ }^{2, d}$ \\ ${ }^{1}$ Roma Tre University, Department of Engineering, Via Vito Volterra 62, 00146 Rome, Italy. \\ ${ }^{2}$ University of Minho, ISISE, Department of Civil Engineering, Azurém P-4800-058, Guimarães, Portugal. \\ ${ }^{\text {a }}$ E: gianmarco.defelice@uniroma3.it. T: +39065733 6268. F: +39 065733 3441. * Corresponding author. \\ bE: stefano.desantis@uniroma3.it. T: +39065733 6387.F: +39065733 3441. \\ 'E: pbl@civil.uminho.pt. T: +351 253510200. F: +351 253510217. \\ dE: nunomendes@civil.uminho.pt. T: +351 253510200. F: +351 253510217.
}

\section{Running Head}

Seismic assessment of historic masonry structures

\begin{abstract}
Despite the high vulnerability to earthquakes of existing masonry structures, the available approaches for evaluating seismic demand and capacity still appear inadequate and there is scarce consensus amongst researchers on the most appropriate assessment methods to use. Aiming at developing an improved knowledge about the seismic behaviour of masonry structures and on the reliability of numerical analysis tools, two real-scale masonry specimens were tested on a shake table. Several experts were invited to foresee the failure mechanism and seismic capacity of these specimens within a blind prediction test initiative. Once unveiled, experimental results were simulated a posteriori making use of multi-block dynamics, finite elements or discrete elements. In this paper, the different approaches are discussed, in order to gather the lessons learned and to identify issues requiring further attention. The comparisons amongst shake table test results, predictions and postdictions indicated that a combination of engineering judgement and numerical models may help to identify the collapse mechanism, which is as essential as challenging for the out-of-plane seismic safety assessment. To this purpose, discrete modelling approaches may lead to more reliable results that continuous ones. Once the correct mechanism is identified, the estimate of the seismic capacity remains difficult, due to the complexity and randomness of the seismic response, and to the sensitivity of numerical tools to variables not always with a clear physical meaning. At present state of knowledge, it appears that simplified approaches based on rigid body dynamics, even if they require considerable experience and engineering judgment, may provide as good results as advanced simulations.
\end{abstract}

\section{Keywords}

Masonry, Seismic assessment, Out-of-plane, Shake table testing, Blind test prediction, Rigid-body dynamics, Discrete Element Method, Finite Element Method, Limit analysis.

\section{INTRODUCTION}

Out-of-plane overturning is one of the main causes of damage or collapse induced by earthquakes on existing masonry structures. The vulnerability of perimeter walls under out-of-plane seismic loading characterizes 
especially historic buildings, which do not exhibit a box-type behaviour due to the low strength and deterioration of materials, to the lack of adequate arrangement of the units, of structural details (proper connections between orthogonal walls), and of retrofitting devices (e.g., steel tie-bars) (Lourenço et al., 2011). Despite the numerous studies carried out so far (a state-of-the-art review is provided by Ferreira et al., 2015 and by Sorrentino et al., 2016), numerous issues are still unresolved and scarce consensus exists amongst experts on the most appropriate methods to use for seismic safety assessment.

The difficulty of describing the dynamic behaviour and assessing the seismic performance of masonry structures relies on (i) the heterogeneity and anisotropy of masonry, (ii) the brittle nature of cracking phenomena and the discontinuous behaviour of cracked structures, (iii) the strongly non-linear response of rocking masonry walls, and (iv) the uncertainties related to the demand (earthquake input) and the capacity (Mendes and Lourenço, 2014). Examples of difficulties in determining the capacity are the actual arrangement of brick/stones both in the wall thickness and at the corners with orthogonal walls, the mechanical properties and deterioration of materials, the unknown structural details, foundations and soil, among others.

Assessment methods often used provide a simplified description of the static response of existing masonry structures, modelled as an assembly of rigid blocks separated by hinges. A suitable representation of their dynamic behaviour is generally not attempted, other than through a behaviour factor that accounts for the dynamic reserve of stability (Sorrentino et al., 2016). Nevertheless, the reliability of these approaches relies on the identification of the correct collapse mechanism, which is a highly challenging task. Firstly, the most probable mechanism(s) should be considered amongst all the possible mechanisms, excluding the unrealistic ones that would lead to over-conservative results. This requires a good knowledge of the structural elements and details, to include in the assessment contributions such as connections with floor and walls, and tie-bars and bond-beams (which improve the structural safety), or thrust from vaults and roofs (which have instead a destabilizing effect). Secondly, the actual behaviour of the wall may differ largely from that of the monolithic one assumed in limit analysis based approaches. If leaf separation or wall disaggregation occurs due to the poor mechanical properties of the materials or to the arrangement of the units (lack of transversal headers or of horizontal bed joints, small stones, etc.), multi-block models may be strongly unconservative (de Felice, 2011).

As an alternative to limit analysis based methods, more complicated modelling approaches with Finite Elements or Distinct Elements have been developed, also thanks to the advancement of calculation tools. So far, however, they have been mainly used for research purposes due to their high computational cost and advanced knowledge required to define properly material properties, discretization, damping, boundary conditions, input parameters, etc., which make them less suitable for engineering professional applications. Aiming at improving the current knowledge and at discussing open issues, a workshop titled "Methods and challenges on the out-of-plane assessment of existing masonry buildings" was organized in the framework of the 9th International Masonry Conference, held in Guimarães, Portugal, in July 2014. Shake table tests were carried out on two large-scale U-shaped specimens, made out of a front wall and two side walls, one built with clay bricks and one in stone masonry (Candeias et al., 2016). Several experts were invited to predict the seismic capacity of the two specimens, before experimental outcomes were unveiled (Mendes et al., 2016). At a later time, shake table test results were simulated a posteriori making use of various strategies, ranging from analytical methods based on rigid-body mechanisms (Derakhshan et al., 2016), to numerical models with finite elements (Gams et al., 2016; Chácara et al., 2016), discrete elements (Lemos et al., 2016; Cannizzaro and Lourenço, 2016), and combined finite-discrete elements (Sorrentino et al., 2016). Static and dynamic analyses were carried out to reproduce the failure mechanism, and to simulate the experimental response. This paper recalls and discusses the main steps of this process to gather the lessons learned, which may help developing recommendations addressed to practitioners, and may help identifying issues requiring further attention and may orient future research activities.

\section{SHAKE TABLE TESTS OUTCOMES}

A shake table investigation was carried out at LNEC, Lisbon, Portugal, on two U-shaped masonry structures (Candeias et al., 2016). The specimens were made out of a $3.50 \mathrm{~m}$ wide and $2.75 \mathrm{~m}$ high façade (named East wall) and two $2.50 \mathrm{~m}$ wide and $2.25 \mathrm{~m}$ high transverse walls (South and North walls). One of the specimens (named Brick House) was built with standard clay bricks and cement mortar, had $0.235 \mathrm{~m}$ thick walls (slenderness ratio about 1:10) and presented a window on the East and the North wall (Figure 1a). The other specimen (Stone House) was realized with large stones (with the longer side of up to about $1 \mathrm{~m}$ ) and lime 
mortar, had $0.50 \mathrm{~m}$ wide multi-leaf walls (with a weaker inner core, slenderness ratio about 1:5), a door in the façade and a window in the North wall (Figure 1b). In both specimens, the South wall was blind (with no openings) and the façade had a gable on top. Finally, units (either bricks or stones) were arranged to provide interlocking at the corners. Given the unit-to-structure size ratio, the Brick House could be possibly better assimilated to a continuum system, whilst the Stone House is meant to be governed by the actual arrangement of the stones and the location of the joints. Given the slenderness ratios, the former is also expected to be more flexible than the latter.

The record of the N64E strong ground motion component of the 21/02/2011 Christchurch, New Zealand earthquake was used as seismic input and was applied in the direction normal to the front wall (tests were unidirectional). The original signal was filtered and cut and the resulting input had 27s duration, 0.28g PGA (Peak Ground Acceleration), 236mm/s PGV (Peak Ground Velocity) and 25.8mm PGD (Peak Ground Displacement). The input was applied with increasing scaling factor starting from $100 \%$ up to the collapse, which was attained at a recorded PGA of $1.27 \mathrm{~g}$ by the Brick House ( 8 tests) and $1.07 \mathrm{~g}$ by the Stone House (6 tests). The main results are recalled in Figure 2, while for all of them the reader is addressed to (Candeias et al., 2016). It was reported that, in both specimens, the façade behaved as a nearly-rigid body for relatively low excitations, as revealed by the small dynamic amplification (ratio between the maximum acceleration recorded on the walls and that on the table). On the Brick House, when approaching collapse (in the last two tests), values of dynamic amplification of 1.9 and 2.2 were calculated on top of the gable and at the North corner, respectively (Figure 2a). In the Stone House, the dynamic amplification before collapse was 2.0-2.9 (Figure 2c). Additionally, non-negligible residual displacements were measured, associated to permanent dislocations of some portions on top of the specimen, separated from the underlying walls by cracks. Surveyed damage, dynamic amplifications, and residual dislocations were observed to be higher and to evolve faster in the Stone House than in the Brick House. This latter exhibited lower top-to-bottom relative displacements than the former for comparable input intensity (Figures $2 b, d$ ). The maximum displacement recorded at the top of the façade in the most severe test was $219 \mathrm{~mm}$ for the Stone House $(9.7 \%$ of the height of the wall) and $136 \mathrm{~mm}$ for the Brick House (6\% of the height of the wall), but, in this latter case, the measurement was truncated by the collapse of the gable.

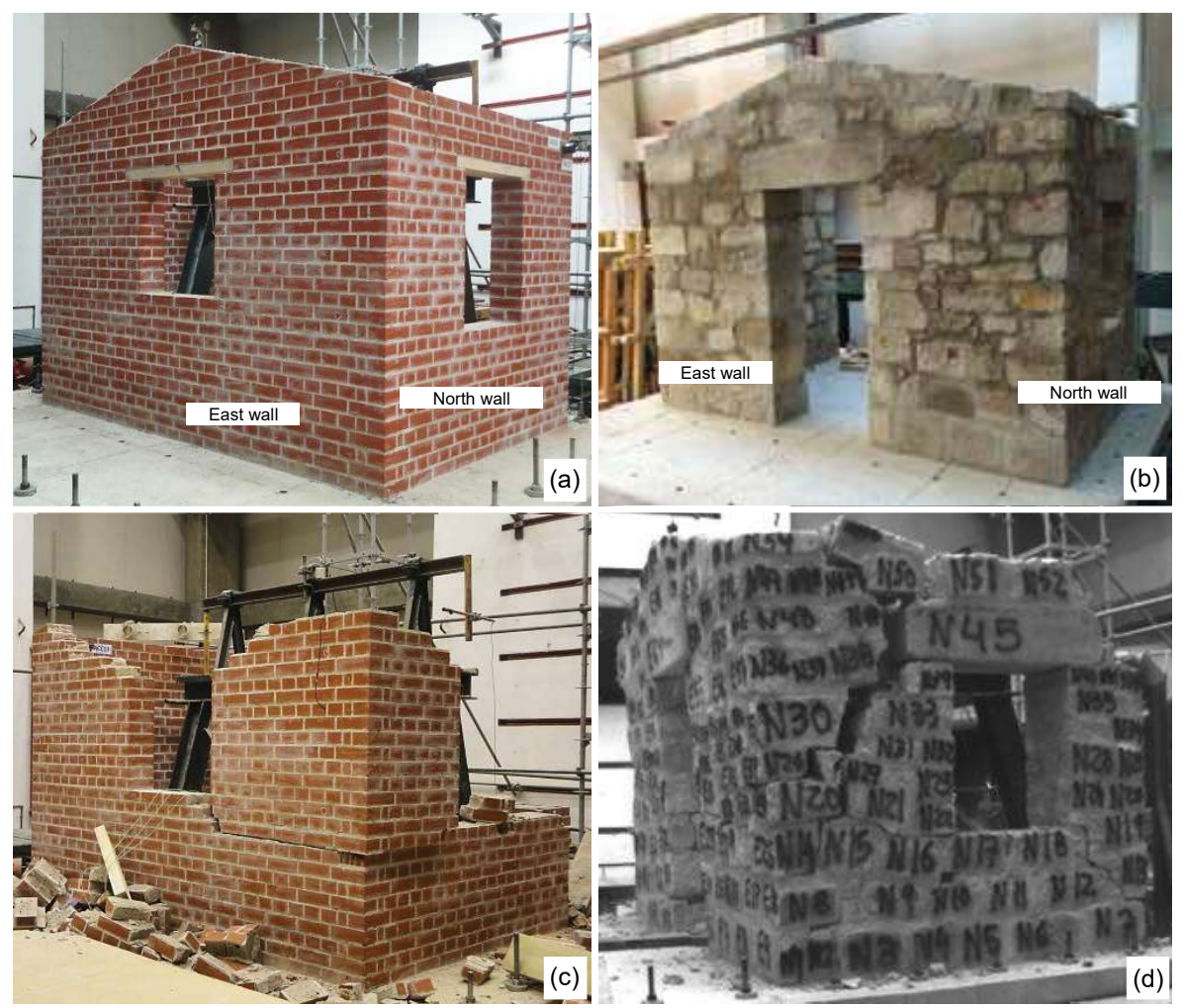

Figure 1. Brick House $(\mathrm{a}, \mathrm{c})$ and Stone House $(\mathrm{b}, \mathrm{d})$ specimens before the beginning of the shake table tests $(\mathrm{a}, \mathrm{b})$ and at collapse $(\mathrm{c}, \mathrm{d})$ (Candeias et al., 2016).

The main failure mechanism of the brick house (collapsed at $\mathrm{PGA}=1.27 \mathrm{~g}$ ) involved the gable, the right side of the façade and the upper part of the North wall (the one provided with the window, Figure 1c). A 
secondary mechanism also activated involved only the gable. The gable separated from the underlying part of the front wall, exhibited a large rocking motion and was the first element to overturn. Displacements were related to rocking and bending deflections of the walls, rather than to dislocations or sliding of the portions separated by cracks. In the Stone House (collapsed at PGA=1.07g), the failure mechanism involved the gable and most of both the façade and the North wall (Figure 1d). Some large stones fell down from the North corner but the lower slenderness of the walls (compared to that of the Brick House) avoided the out-of-plane overturning of large portions, which experienced large rocking motions without collapsing. According to (Candeias et al., 2016), the lower capacity displayed by the Stone House was probably caused by the larger opening in the front wall (a door instead of a window), but the larger mortar joints, the more irregular arrangement, and the presence of the weaker inner core could also have had some influence on this result. On the other hand, the larger units and the lower slenderness led to large stone dislocations and, therefore, to larger displacements than those exhibited by the Brick House. Finally, the presence of one blind wall (South side) and one wall with a window opening (North side) caused torsional effects. An asymmetric collapse mechanism activated, and damage mainly concentrated on the North wall (even if in-plane damage only appeared under strong inputs) and on the North corner.
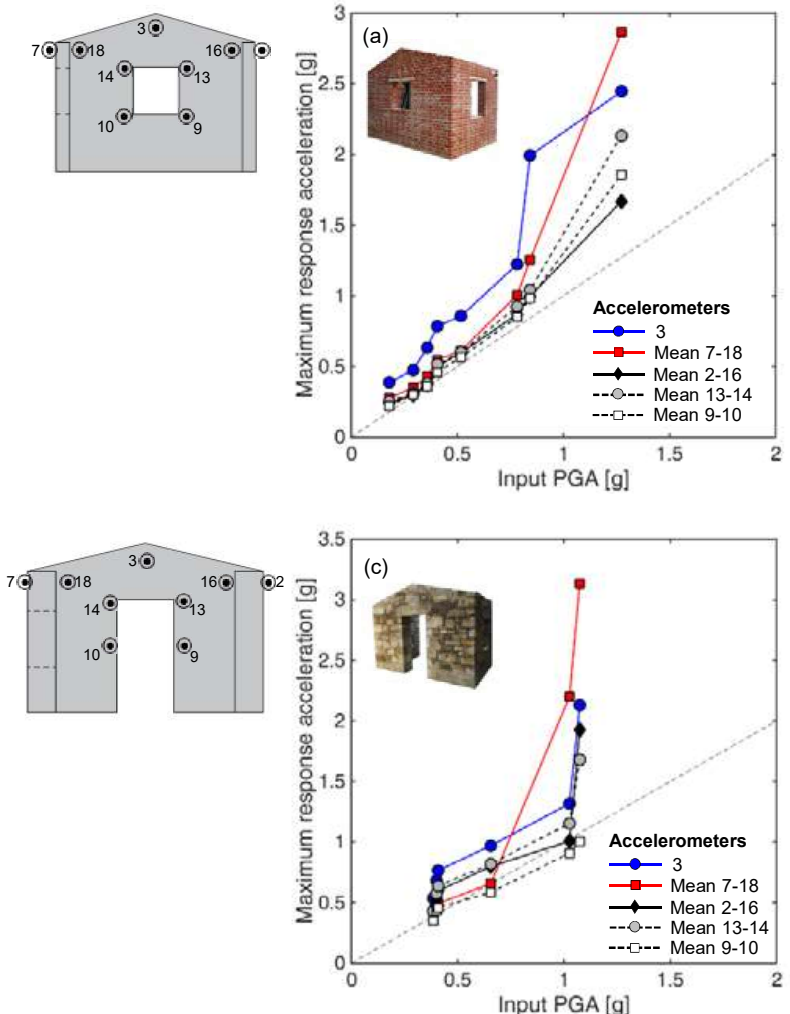
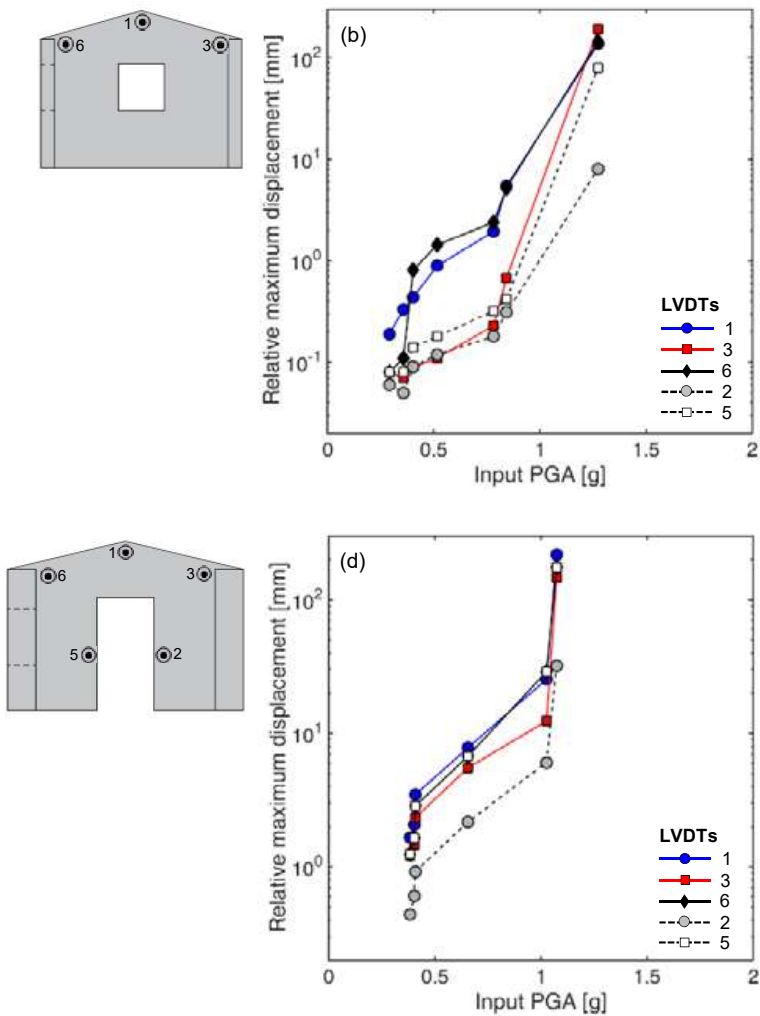

Figure 2. Results of shake table tests on Brick House $(a, b)$ and Stone House $(c, d)$ : maximum accelerations and dynamic amplification $(\mathrm{a}, \mathrm{c})$, and top-to-bottom relative displacements (b,d) (Candeias et al., 2016). (Interior view)

The shake table tests provided important information and constituted the starting point for evaluating the reliability of different assessment methods, as discussed hereafter. Similarly, the experimental investigations carried out in the last two decades on shake tables have significantly contributed to the knowledge on the seismic out-of-plane behaviour of masonry structures (see, amongst others: Bothara et al., 2010; Mendes and Lourenço, 2010; AlShawa et al., 2012; Costa et al., 2013; Mendes et al, 2014), and helped developing innovative masonry building systems (Lourenço et al., 2013) and reinforcement solutions (see, amongst others: Benedetti et al., 1998; De Santis et al., 2016; De Canio et al., 2016). Complexity, cost and time efforts, and the difficult interpretation of results have however limited the intensive use of shake table tests, while many simpler investigations were carried out with static or pseudo-dynamic setups. Indeed, shake table tests differ by their very nature from real situations, posing questions on the interpretation of the results. First, one or few selected signals are used as input and, despite the number of seismic intensity measures proposed, including the Root Mean Square (RMS) acceleration, the Spectral pseudo-acceleration $\left(\mathrm{S}_{\mathrm{a}}\right)$, the Peak Ground Velocity (PGV), the Maximum Incremental Velocity (MIV), the Velocity Spectrum Intensity (VSI) (Sorrentino et al., 2006), the structural response remains strongly sensitive to the characteristics of the 
ground motion. Second, shake table sessions generally include several tests performed with the same input(s) that are progressively scaled up. Therefore, collapse is not actually induced by the last input, but by the entire sequence, since damage accumulates progressively. Thus, the actual capacity appears underestimated, whilst the identification of a single input equivalent to the whole sequence seems impossible. Third, the structural model built in the laboratory, even if full-scale, differs from real structures for size (real structures are clearly much larger), materials (also lack of deterioration) and accuracy in representing the complex reality. In this case, the experimental capacity exhibited in the literature is likely to be higher than the one observed after earthquakes, suggesting that real structures may be weaker than the specimens built in the laboratory. Finally, the variability of the complex phenomena under investigation raises doubts on the repeatability of test results.

\section{BLIND TEST PREDICTIONS}

Aiming at evaluating the capability of the different tools available for the out-of-plane assessment of masonry walls, several experts were invited to estimate the seismic capacity (in terms of collapse PGA) of the two specimens tested on the shake table and provide a blind test prediction (Mendes et al., 2016). Research groups were provided with the geometry and mass of the specimens, the mechanical properties of the two masonry types (compressive and shear strength, derived experimentally by the organizers) and the characteristics of the input (normalized response spectrum and envelop of the signal recorded on the shake table during the test). Various modelling approaches and assessment methods were used, and their results differed widely in terms of predicted failure mechanisms and seismic capacity.

\subsection{Modelling approaches and assessment methods}

Mendes et al. (2016) report that different modelling approaches were used depending on individual expertise (Tables 1-2), for a total of 36 predictions of the seismic capacity, 17 for the Brick House and 19 for the Stone House. Most of them (23/36) were performed with rigid block analysis. Since no information was available on the experimental failure mechanism, blind predictions were based either on personal judgement (11/23) or on preliminary finite elements or discrete elements models (12/23). Methods based on rigid block analysis represented the mechanism with a single-degree-of-freedom (SDOF) system subjected to the horizontal static loads in addition to the self-weight. The collapse condition was then calculated by equilibrium equations or with the principle of virtual works, with either a static or a kinematic approach. In the static approach, the capacity was estimated as the PGA that activates the mechanism and the demand was derived from the acceleration response spectrum, taking into account the dynamic amplification through the structure and the reserve of stability from the activation of the mechanism to the out-of-plane overturning. In the kinematic approach, the seismic capacity was identified by means of a non-linear analysis, leading to a capacity curve whose ultimate point identified the maximum attainable displacement at collapse. The demand was derived from the displacement response spectrum, calculating a fundamental period of the equivalent SDOF system. One prediction was performed by integrating the equation of motion of a rigid block under earthquake base motion and the PGA was calculated as that inducing instability.

Numerical models with finite elements (FEM, with either macro- or micro-modelling approaches), distinct elements (DEM), or combined finite-discrete elements (FEM/DEM) were used to predict the mechanism and/or to assess the seismic capacity (9 FEM and 4 DEM). In finite element macro-models, the masonry was described as an equivalent homogeneous material (Figure 3a), while in micro-modelling (Figure 3b), the units were represented explicitly and the joints were described by interfaces, where cracking is allowed. To reduce computational costs, larger-than-real units were defined. Distinct element models were used either in 2D (Figure 3c) or in 3D (Figure 3d), to achieve a suitable representation of rigid body motions and relative sliding occurring after cracking. The former approach (2D) allowed for a detailed representation of the actual shape of each block and joint, and was performed in the plane of the North wall (side wall provided with the opening), assuming that the façade was subjected to a nearly-rigid body out-of-plane overturning behaviour. The latter, being performed in $3 \mathrm{D}$, simulated the out-of-plane bending of the façade and the torsional behaviour of the entire specimen, but made use of a simplified geometrical representation (a single leaf wall made out of brick shaped blocks) to reduce runtime. In DEM, the mortar joints were modelled as zero thickness interfaces between rigid blocks, and were provided with non-linear relationships between contact force and relative displacement. Differently from limit analysis based approaches, with FEM and DEM the 
failure mechanism was identified directly by the model. Analyses were either static (pushover) under horizontal loads, or dynamic with time-step integration under artificial accelerograms compliant with the response spectrum provided. In the former case (pushover), the capacity was assessed as the peak of the response curve, whilst in the latter, simulations were carried out under increasing intensity of the input (incremental dynamic analysis, IDA) up to a given definition of failure, and the PGA of the last run was taken as the seismic capacity.

Table 1. Predictions for the Brick House.

\begin{tabular}{|c|c|c|c|c|c|c|}
\hline Participant & Mechanism $^{(1)}$ & $\begin{array}{c}\text { PGA } \\
{[\mathrm{g}]}\end{array}$ & $\begin{array}{l}\text { Modelling } \\
\text { approach }\end{array}$ & $\begin{array}{l}\text { Evaluation } \\
\text { of capacity }\end{array}$ & $\begin{array}{c}\text { Assessment } \\
\text { method }\end{array}$ & Notes \\
\hline \multicolumn{2}{|c|}{ Experimental } & \multicolumn{5}{|l|}{1.27} \\
\hline \multirow{2}{*}{ A } & 2 & 0.30 & $\mathrm{RB}$ & $\begin{array}{l}\text { S (non- } \\
\text { linear) }\end{array}$ & DB & \multirow{2}{*}{$\begin{array}{l}\text { Failure mechanism identified by personal judgment. } \\
\text { Collapse displacement predicted through } \\
\text { displacement response spectrum. Collapse PGA } \\
\text { estimated through time history analyses. } \\
\text { Postdiction performed (\$4.1.) }\end{array}$} \\
\hline & 7 & 0.35 & $\mathrm{RB}$ & $\begin{array}{l}\mathrm{D} \text { (non- } \\
\text { linear) }\end{array}$ & FB & \\
\hline B & 4 & 0.75 & RB & S (linear) & FB & Failure mechanism identified by personal judgment. \\
\hline $\mathrm{C}$ & 2 & 1.00 & $\mathrm{RB}$ & $\mathrm{S}$ (linear) & DB & $\begin{array}{l}\text { Failure mechanism identified by personal judgment. } \\
\text { Collapse PGA predicted with the capacity spectrum } \\
\text { method as that corresponding to a spectral } \\
\text { displacement equal to } 40 \% \text { of the instable } \\
\text { equilibrium displacement. }\end{array}$ \\
\hline \multirow{2}{*}{ E } & 2 & 0.37 & $\mathrm{RB}$ & PVW & FB & \multirow{2}{*}{$\begin{array}{l}\text { Failure mechanism identified by personal judgment. } \\
\text { Collapse PGA predicted with a force-based approach } \\
\text { that makes use of the Principle of Virtual Works, } \\
\text { also including dynamic amplification, or with a } \\
\text { displacement-based approach. }\end{array}$} \\
\hline & 2 & 0.39 & $\mathrm{RB}$ & PVW & DB & \\
\hline \multirow[b]{2}{*}{$\mathrm{F}$} & 3 & 0.42 & $\begin{array}{c}\mathrm{FEM} / \mathrm{DEM} \\
+\mathrm{RB}\end{array}$ & IDA & DB & \multirow{2}{*}{$\begin{array}{l}\text { Failure mechanism identified by FE model running } \\
\text { non-linear dynamic analyses under artificial } \\
\text { accelerogram. Collapse PGA predicted on an } \\
\text { equivalent SDOF system with a displacement-based } \\
\text { or a force-based approach. } \\
\text { Postdiction performed (\$4.4.) }\end{array}$} \\
\hline & 3 & 0.95 & $\begin{array}{c}\text { FEM/DEM } \\
+\mathrm{RB}\end{array}$ & IDA & FB & \\
\hline \multirow{2}{*}{$\mathrm{G}$} & 1 & 0.40 & $\begin{array}{l}\text { FEM- } \\
\text { macro }\end{array}$ & IDA & FB & \multirow{2}{*}{$\begin{array}{l}\text { Failure mechanism identified by FE model. Non- } \\
\text { linear dynamic analyses performed. Collapse PGA } \\
\text { predicted as that of the accelerogram used in the } \\
\text { analysis in which convergence is lost, or with } \\
\text { pushover analyses under mass proportional loads. }\end{array}$} \\
\hline & 1 & 0.60 & $\begin{array}{l}\text { FEM- } \\
\text { macro }\end{array}$ & POA & FB & \\
\hline $\mathrm{H}$ & 6 & 0.86 & $\begin{array}{c}\text { FEM- } \\
\text { macro + } \\
\text { RB }\end{array}$ & $\begin{array}{l}\text { S (non- } \\
\text { linear) }\end{array}$ & DB & $\begin{array}{l}\text { Failure mechanism identified by FE model. Collapse } \\
\text { PGA predicted with limit analysis on rigid-block } \\
\text { system. }\end{array}$ \\
\hline \multirow{5}{*}{ I } & 5 & 0.57 & $\begin{array}{l}\text { FEM- } \\
\text { macro }+ \\
\text { RB }\end{array}$ & PVW & FB & $\begin{array}{l}\text { Failure mechanism identified by personal judgment. } \\
\text { Collapse PGA predicted with a force-based approach } \\
\text { that makes use of the Principle of Virtual Works. }\end{array}$ \\
\hline & 8 & 0.75 & $\begin{array}{l}\text { FEM- } \\
\text { macro }\end{array}$ & POA & FB & \multirow{2}{*}{$\begin{array}{l}\text { Failure mechanism identified by FE model. Collapse } \\
\text { PGA predicted with pushover analyses under mass } \\
\text { proportional loads (two software programs used). }\end{array}$} \\
\hline & 8 & 0.76 & $\begin{array}{l}\text { FEM- } \\
\text { macro }\end{array}$ & POA & FB & \\
\hline & 5 & 1.00 & DEM & IDA & FB & $\begin{array}{l}\text { Failure mechanism identified by personal judgement } \\
\text { and DE model. Non-linear dynamic analyses } \\
\text { performed. Collapse PGA predicted as that of the } \\
\text { accelerogram used in the analysis in which } \\
\text { convergence is lost. }\end{array}$ \\
\hline & 8 & 1.00 & $\begin{array}{l}\text { FEM- } \\
\text { macro }\end{array}$ & IDA & FB & $\begin{array}{l}\text { Failure mechanism identified by personal judgement } \\
\text { and FEM model. Non-linear dynamic analyses } \\
\text { performed. Collapse PGA predicted as that of the } \\
\text { accelerogram used in the analysis in which } \\
\text { convergence is lost. }\end{array}$ \\
\hline K & 2 & 0.47 & $\begin{array}{l}\text { FEM- } \\
\text { micro }\end{array}$ & POA & FB & $\begin{array}{l}\text { Failure mechanism identified with FE model. } \\
\text { Collapse PGA predicted with a force-based approach } \\
\text { that makes use of the Principle of Virtual Works, } \\
\text { including elastic deformability. } \\
\text { Postdiction performed (\$4.2.) }\end{array}$ \\
\hline
\end{tabular}

PGA: peak ground acceleration at collapse; RB: limit analysis with rigid-body systems; FEM -micro/-macro: Finite Element Method with micro-/macro- modelling approaches; DEM: Distinct Element Method; S: static analysis; D: dynamic analysis; PVW: principle of virtual works; POA: pushover analysis; IDA: incremental dynamic analysis (time-step integration under earthquake base motion).

(1) The reader is addressed to (Mendes et al., 2016) for the predicted failure mechanisms and their numbering. 
Table 2. Predictions for the Stone House.

\begin{tabular}{|c|c|c|c|c|c|c|}
\hline Participant & Mechanism $^{(1)}$ & $\begin{array}{c}\text { PGA } \\
{[\mathrm{g}]}\end{array}$ & $\begin{array}{l}\text { Modelling } \\
\text { approach }\end{array}$ & $\begin{array}{l}\text { Evaluation } \\
\text { of capacity }\end{array}$ & $\begin{array}{c}\text { Assessment } \\
\text { method }\end{array}$ & Notes \\
\hline \multicolumn{2}{|l|}{ Experimental } & \multicolumn{5}{|l|}{1.07} \\
\hline A & 4 & 0.60 & $\mathrm{RB}$ & $\begin{array}{l}\text { S (non- } \\
\text { linear) }\end{array}$ & DB & $\begin{array}{l}\text { Failure mechanism identified by personal } \\
\text { judgment. Collapse displacement predicted through } \\
\text { displacement response spectrum. } \\
\text { Postdiction performed (\$4.1.) }\end{array}$ \\
\hline B & 3 & 0.95 & $\mathrm{RB}$ & S (linear) & FB & $\begin{array}{l}\text { Failure mechanism identified with personal } \\
\text { judgment. }\end{array}$ \\
\hline \multirow[t]{2}{*}{$\mathrm{C}$} & 5 & 2.00 & $\mathrm{RB}$ & S (linear) & DB & \multirow{2}{*}{$\begin{array}{l}\text { Two collapse mechanism identified by personal } \\
\text { judgment. Collapse PGA predicted with the } \\
\text { capacity spectrum method as that corresponding to } \\
\text { a spectral displacement equal to } 40 \% \text { of the instable } \\
\text { equilibrium displacement. }\end{array}$} \\
\hline & 6 & 2.50 & $\mathrm{RB}$ & S (linear) & DB & \\
\hline \multirow{2}{*}{$\mathrm{D}$} & 8 & 0.60 & DEM & IDA & FB & \multirow{2}{*}{$\begin{array}{l}\text { Two failure mechanisms were identified by } \\
\text { personal judgement and DE 3D model with non- } \\
\text { linear dynamic analyses, mainly performed to } \\
\text { investigate progressive damage development. For } \\
\text { one of them (\#9) collapse PGA was predicted with } \\
\text { pushover analysis, while for the other (\#8) collapse } \\
\text { PGA prediction was not attempted. } \\
\text { Postdiction performed (\$4.3.) }\end{array}$} \\
\hline & 9 & 0.65 & DEM & POA & FB & \\
\hline \multirow{2}{*}{ E } & 10 & 0.53 & $\mathrm{DEM}+\mathrm{RB}$ & PVW & FB & \multirow{2}{*}{$\begin{array}{l}\text { Failure mechanism identified by DEM 2D. } \\
\text { Collapse PGA predicted with a force-based } \\
\text { approach (also including dynamic amplification) or } \\
\text { a displacement-based approach that make use of the } \\
\text { Principle of Virtual Works. }\end{array}$} \\
\hline & 10 & 0.89 & $\mathrm{DEM}+\mathrm{RB}$ & PVW & DB & \\
\hline \multirow{4}{*}{$\mathrm{F}$} & 11 & 0.58 & $\begin{array}{c}\mathrm{FEM} / \mathrm{DEM} \\
+\mathrm{RB}\end{array}$ & IDA & FB & \multirow{4}{*}{$\begin{array}{l}\text { Two possible failure mechanism identified by FE } \\
\text { model running non-linear dynamic analyses under } \\
\text { artificial accelerogram. Collapse PGA predicted } \\
\text { with an equivalent SDOF system with a force-based } \\
\text { or displacement-based approach. } \\
\text { Postdiction performed (\$4.4.) }\end{array}$} \\
\hline & 11 & 0.92 & $\begin{array}{c}\text { FEM/DEM } \\
+\mathrm{RB}\end{array}$ & IDA & DB & \\
\hline & 13 & 0.87 & $\begin{array}{c}\mathrm{FEM} / \mathrm{DEM} \\
+\mathrm{RB}\end{array}$ & IDA & FB & \\
\hline & 13 & 1.42 & $\begin{array}{c}\text { FEM/DEM } \\
+\mathrm{RB}\end{array}$ & IDA & DB & \\
\hline \multirow{2}{*}{ G } & 1 & 0.30 & $\begin{array}{l}\text { FEM- } \\
\text { macro }\end{array}$ & IDA & FB & \multirow{2}{*}{$\begin{array}{l}\text { Failure mechanism identified by FE model. } \\
\text { Collapse PGA predicted either with non-linear } \\
\text { dynamic analyses as that of the accelerogram used } \\
\text { in the analysis in which convergence is lost, or with } \\
\text { pushover analyses under mass proportional loads }\end{array}$} \\
\hline & 1 & 0.80 & $\begin{array}{l}\text { FEM- } \\
\text { macro }\end{array}$ & POA & FB & \\
\hline $\mathrm{H}$ & 5 & 0.49 & $\begin{array}{l}\text { FEM- } \\
\text { macro } \\
+\mathrm{MB}\end{array}$ & $\begin{array}{l}\text { S (non- } \\
\text { linear) }\end{array}$ & DB & $\begin{array}{l}\text { Failure mechanism identified by FE model. } \\
\text { Collapse PGA predicted with limit analysis on } \\
\text { rigid-block system. }\end{array}$ \\
\hline \multirow[b]{2}{*}{ I } & 7 & 0.22 & $\begin{array}{l}\text { FEM- } \\
\text { macro } \\
+\mathrm{RB}\end{array}$ & PVW & FB & $\begin{array}{l}\text { Failure mechanism identified by personal } \\
\text { judgment. Collapse PGA predicted with a force- } \\
\text { based approach, making use of the Principle of } \\
\text { Virtual Works. }\end{array}$ \\
\hline & 12 & 1.40 & DEM & IDA & FB & $\begin{array}{l}\text { Failure mechanism identified by personal } \\
\text { judgement and DE model. Non-linear dynamic } \\
\text { analyses performed. Collapse PGA predicted as that } \\
\text { of the accelerogram used in the analysis in which } \\
\text { convergence is lost. }\end{array}$ \\
\hline $\mathrm{J}$ & 2 & 0.38 & $\mathrm{RB}$ & RS & DB & $\begin{array}{l}\text { Failure mechanism identified by personal } \\
\text { judgment. Collapse displacement predicted through } \\
\text { displacement response spectrum }\end{array}$ \\
\hline K & 11 & 1.11 & FEM-micro & POA & FB & $\begin{array}{l}\text { Failure mechanism identified by FE model. } \\
\text { Collapse PGA predicted with a force-based } \\
\text { approach that makes use of the Principle of Virtual } \\
\text { Works, including elastic deformability. } \\
\text { Postdiction performed (\$4.2.) }\end{array}$ \\
\hline
\end{tabular}

PGA: peak ground acceleration at collapse; RB: limit analysis with rigid-body systems; FEM -micro/-macro: Finite Element Method with micro-/macro- modelling approaches; DEM: Distinct Element Method; S: static analysis; D: dynamic analysis; PVW: principle of virtual works; POA: pushover analysis; IDA: incremental dynamic analysis (time-step integration under earthquake base motion). (1) The reader is addressed to (Mendes et al., 2016) for the predicted failure mechanisms and their numbering. 

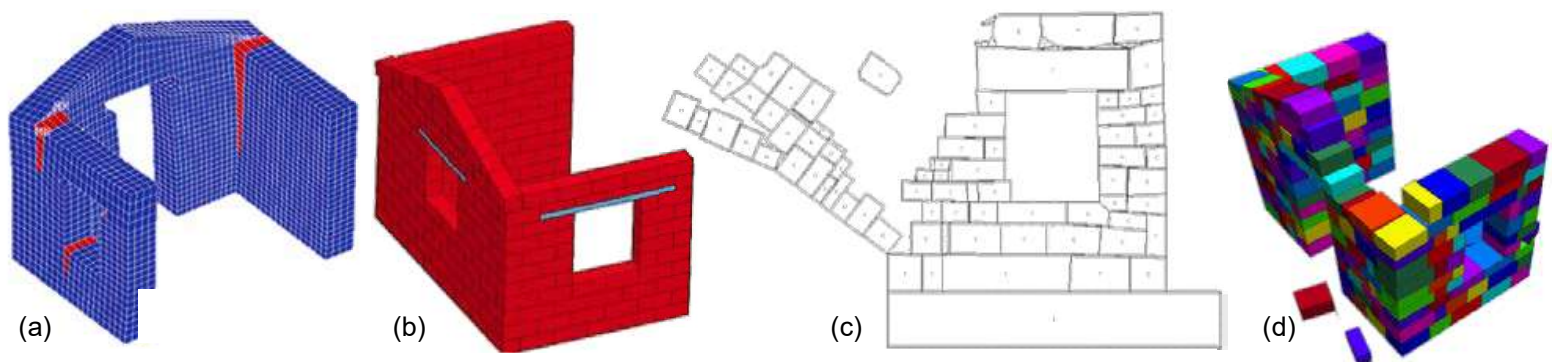

Figure 3. Modelling approaches: Finite Elements macro-modelling (a) and micro-modelling (b), and Distinct Elements in 2D with detailed representation of stone units (c) and in 3D with simplified representation of masonry arrangement (d).

\subsection{Prediction of the collapse mechanism}

Eight collapse mechanisms were predicted for the Brick House, while thirteen mechanisms were predicted for the Stone House (Mendes et al., 2016). Predictions varied widely, mainly depending on the assumption by the experts related to (i) the effectiveness of the connections between front and side walls at the corners, (ii) the bending strength of the façade, and (iii) the in-plane strength of side walls.

(i) For both specimens, shake table tests showed that the arrangement of the units provided an effective connection between orthogonal walls. This prevented cracking at the corners and ensured a constraint at the vertical edges of the façade, which experienced out-of-plane bending. Some predictions correctly foresaw such mechanism, while others neglected or underestimated the effectiveness of the connections and assumed the development of a crack at the corners separating the side walls from the façade, which was free to undergo rocking up to overturning. Disregarding the proper connections at the corners also led to ignoring the effects of bending on the façade and to underestimating the in-plane loading of the side walls.

(ii) Given the effective side connections, the failure mechanism activated on the front wall was governed by its bending strength, which, in its turn, was affected by the weak element represented by the opening. Some predictions included the out-of-plane overturning of the gable, while others included a much larger portion of the façade, but most of them took this issue into account.

(iii) The in-plane strength of the lateral walls affected the actual constraint at the edges of the façade and the volume of the side walls that could be involved in the overturning mechanism, whose weight had a stabilizing effect on the out-of-plane rotation of the façade, especially in the Stone House. Most of the proposed collapse mechanisms that included damage in the side walls accounted for the torsional behaviour induced by the asymmetry of the specimens.

Based on their capability of foreseeing the above features of the experimental failure mechanism, Mendes et al. assessed as good two (out of 8) failure mechanisms for the Brick House (\#2 and \#7), and five (out of 13) of the Stone House (\#9-13). Good mechanisms were identified by 6/17 predictions for the Brick House (35\%) and 9/19 for the Stone House (47\%). As indicated by these percentages, predicting the collapse mechanism of the Brick House resulted more challenging than for the Stone House, due to the higher slenderness and flexibility of the walls, causing large rotations of the North corner. The activation of a secondary mechanism involving the gable only, occurring before that of the larger portion involved in the main failure mode, further complicated the task. As a general trend, the personal judgement of the experts and numerical models with Distinct Elements provided good predictions (especially for the Stone House), indicating that DEM may offer a suitable description of the behaviour at collapse of cracked and relatively stiff structures. Differently, FEM seem to prove less reliable in predicting the bending strength of the façade and the strength of the connections. The continuum nature, intrinsic in FEM, may compromise their reliability when cracked blocky structures experiencing large rigid-body displacements/rotations near collapse are under investigation. Still, it is noted that the experts could not inspect the structures before testing and execution works and condition of the connections play a major role, and could significantly affect the collapse mechanism.

\subsection{Prediction of the seismic capacity}

The predictions of the out-of-plane seismic capacity were scattered, which may be considered by itself a demonstration of the scarce consensus amongst researchers on suitable strategies to handle this problem, as well as of the difficulty of the proposed challenge. As for the Brick House, Mendes et al. (2016) report that 


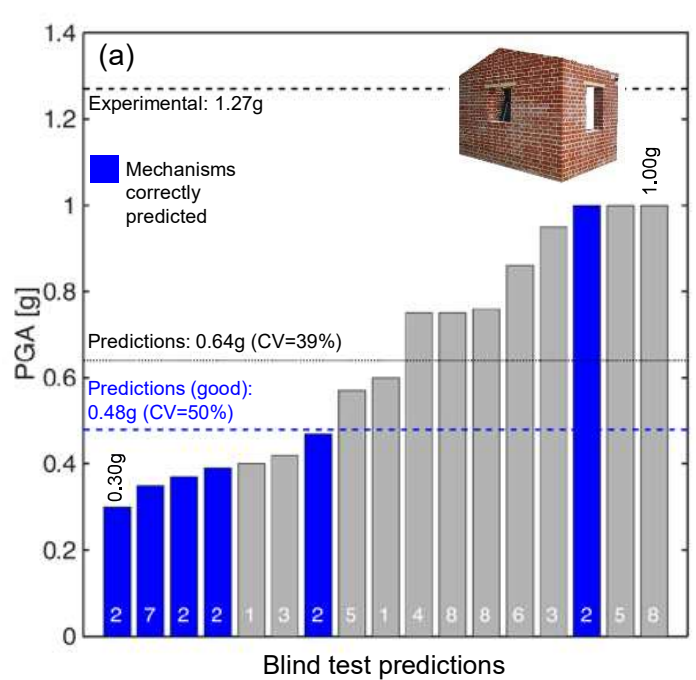

Blind test predictions

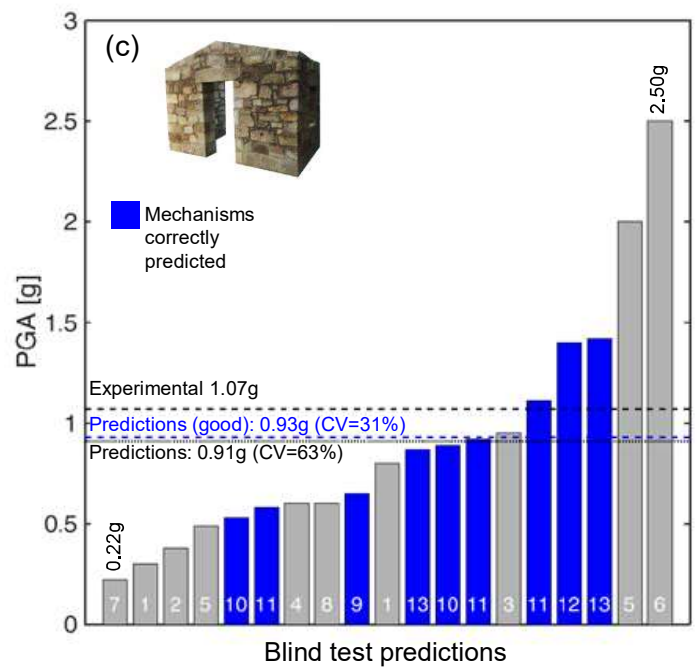
assessed as good are filled in blue.
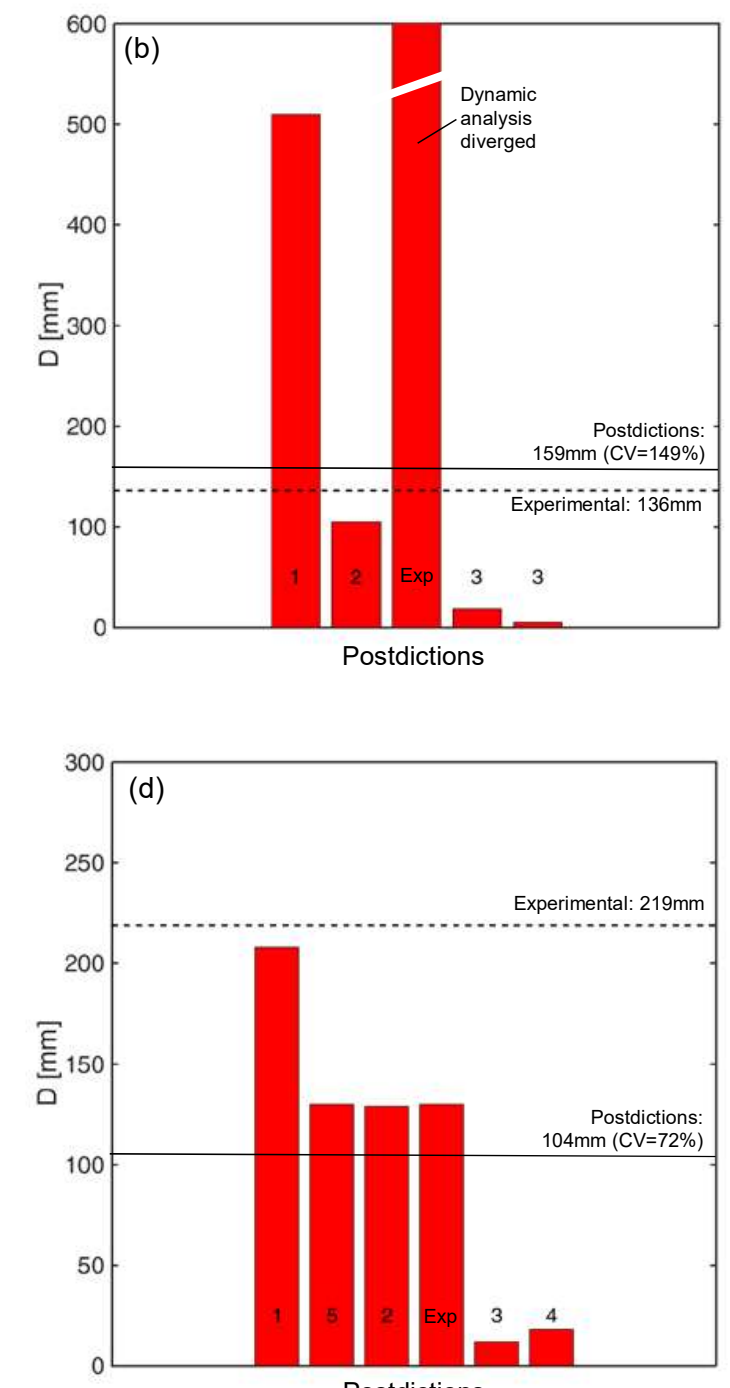

the predicted PGAs ranged between $0.30 \mathrm{~g}$ to $1.00 \mathrm{~g}$, with an average of $0.64 \mathrm{~g}$ ( $49 \%$ lower than the experimental value) and a Coefficient of Variation (CV) of 39\%. If only the good predictions of failure mechanisms (\#2 and \#7) are considered, the mean estimate is $0.48 \mathrm{~g}(\mathrm{CV}=50 \%)$, which is worse than the total mean value (Figure 4a). Better predictions were provided for the Stone House on average (PGA=0.91g, $15 \%$ lower than the experimental value), but with a wider range, from $0.22 \mathrm{~g}$ to $2.50 \mathrm{~g}(\mathrm{CV}=64 \%)$. The good predictions of failure mechanism (\#9-13) led to a slightly better estimate $(0.93 \mathrm{~g}$ and $\mathrm{CV}=31 \%$, Figure $4 \mathrm{c})$. Note that the graphs indicate the failure mechanism corresponding to each prediction and the bars of those

Even though identifying the correct collapse mechanism has to be considered fundamental for a reliable estimate of the seismic capacity, the results of the blind test predictions indicate that this is not enough, since the estimated collapse PGAs differed largely and were mostly incorrect even when a common mechanism was assumed. There was no clear relationship between accuracy of the prediction and modelling approach.

Figure 4. Seismic acceleration capacity provided by blind predictions $(\mathrm{a}, \mathrm{c})$ and seismic displacement demand provided by postdictions $(b, d)$ for Brick House $(a, b)$ and Stone House $(c, d)$. The reader is addressed to (Mendes et al., 2016) for the numbering of predicted failure mechanisms. 


\section{POSTDICTIONS}

Shake table tests were simulated a posteriori by six research groups, making use of various approaches, ranging from analytical methods based on rigid-body mechanisms, to numerical models with finite elements, discrete elements, and combined finite-discrete elements (Tables 3-4). The previously adopted modelling approaches were not used necessarily again by the same groups, as the time constraints were different. Obviously, at this stage, the experimental results were known, making the task much easier than in blind test predictions. In some cases, e.g., with limit analysis, the failure mechanism was assumed as the starting point of the assessment. Alternatively, the capability of the model to estimate both the failure mechanism (Figures 5-8) and the seismic displacement demand was investigated. The experts that run both predictions and postdictions with the same models had the possibility to update them, e.g., by re-calibrating some parameters, in order to match experimental results. Nevertheless, the collapse PGA was not provided by postdictions, which mainly focussed on the assessment of the maximum displacement capacity (Derakhshan et al., 2016) and on the simulation of the displacement response in time (Gams et al., 2016; Lemos and Campos Costa, 2016), while AlShawa et al. (2016) did not go beyond the identification of the failure mechanism. For these reasons, a systematic comparison between predictions and postdictions was not attempted. On the other hand, most postdictions evaluated the seismic displacement demand, which is compared with the displacements recorded in the last tests (at collapse) in Figures $4 \mathrm{~b}$ and $4 \mathrm{~d}$ for the Brick House and for the Stone House, respectively. The displacement simulated in postdictions for the whole shake table sessions, when available, are represented with experimental data in Figure 9. Finally, taking advantage of the time available for postdictions, the sensitivity of the results to some variables, such as meshing, strength properties, analysis parameters, and input characteristics was also investigated in some cases. The failure mechanisms provided by postdictions are basically all correct and do not differ largely from each other (Figures 5-8). All of them represented well the torsional response of the structures, the North wall always being much more cracked than the South wall, whilst the bending strength of the façade resulted underestimated in most cases. Differently, the simulation of the displacement demand at collapse was not completely satisfactory. The average value was $159 \mathrm{~mm}(+17 \%)$ for the Brick House (Figure $4 \mathrm{~b})$ and $104 \mathrm{~mm}$ $(-52 \%)$ for the Stone House (Figure 4d). These values were extremely scattered, the CV being $149 \%$ and $72 \%$. It has however to be considered that displacements (both in shake table tests and in numerical simulations) hugely increased immediately before collapse (Figures $4 \mathrm{~b}, \mathrm{~d}$ and 9 ). Therefore, even a slight underestimate of the capacity seems to lead to a large underestimate of the displacement demand.

\subsection{Limit analysis with equivalent block systems}

Derakhshan et al. used an analytical approach to assess the seismic capacity of the Brick House and the Stone House. The overturning of the gable was simulated for the former (Figure 6, mechanism \#1), while the collapse of the façade (but not the lateral wall) was analysed for the latter (Figure 8, mechanism \#1), so in both cases, the side walls were not included in the model. The portion of the front wall involved in the failure mechanism, known from the experimental results, was modelled as an equivalent Single-Degree-of-Freedom (SDOF) system, namely one rigid block placed on a rigid foundation and experiencing rocking motion around a corner. Based on its shape, the wall that actually collapsed was divided into sub portions (three for the Brick House and four for the Stone House), each of which was subjected (at its centre of mass) to a static horizontal load that simulated the inertial forces arising under earthquake base excitation. The magnitude of these forces was evaluated as the product of mass and modal displacements, considered as linearly increasing with the height (a triangular first mode shape was assumed).

The moment balance equation around the pivot provided the load that activates the mechanism $\left(\mathrm{F}_{0}\right)$ and the displacement of instable equilibrium $\left(\Delta_{\text {ins }}\right)$, referred to the centre of mass of the SDOF. The mass being known, the stiffness $\mathrm{K}=0.75 \mathrm{~F}_{0} / 0.25 \Delta_{\text {ins }}$ was used to derive the elastic period $\mathrm{T}$. Then, the seismic demand was derived as the value corresponding to an abscissa $T$ in the elastic displacement response spectrum of the signals recorded on the shake table in the last input, and resulted $510 \mathrm{~mm}$ for the Brick House and $208 \mathrm{~mm}$ for the Stone House.

The evaluation of the seismic demand via response spectra presents some non-negligible uncertainties. First, it depends on the period $\mathrm{T}$, which, in its turn, relies on a simplified evaluation of an elastic stiffness measure. Furthermore, as the period of a rocking system depends on the amplitude of the oscillations, the authors found that this estimate is reliable only when displacements larger than half the displacement capacity occur (Derakhsham et al., 2016, and references herein). Conversely, this procedure may largely overestimate the 
seismic demand if rocking is not activated, that is, for low intensity excitations (Figure 9). Second, the displacement demand is sensitive to the viscous damping assumed, the spectral displacement varying by up to $50 \%$ when passing from $2 \%$ to $10 \%$ ). The determination of a viscous damping for masonry structures, however, is still an open issue.

\subsection{Finite element method}

Three models were developed with Finite Elements, differing for the level of detail used to represent the units and the mortar joints. A macro-modelling approach was used by Chácara et al. (2016), in which the masonry was modelled as a homogeneous and isotropic equivalent material with limited tensile and shear strength. The Brick House and the Stone House were discretized by 3D finite elements with regular mesh (that is, all the elements had roughly the same size). In the same work, a micro-modelling approach was also used, comprising elastic units and non-linear interfaces with limited compressive and shear strength, requiring a much higher computational effort. Pushover analyses under mass proportional horizontal loads (in direction normal to the façade, both inwards and outwards) and non-linear dynamic analyses under the accelerograms recorded on the shake table were carried out. Both approaches revealed a good agreement with experimental results in terms of failure mechanism for what concerns the side walls (loaded in-plane), but not for the façade (loaded out-of-plane), especially for the Brick House (Figures 5b-c and 7b-c). More specifically, despite catching the torsional response of the asymmetric structure, the numerical simulations overestimated the damage over the opening of the façade (vertical cracks in the middle of the gable) and underestimated that at the base of the gable (nearly horizontal cracks from the opening to the corners, separating the gable from the underlying part of the front wall). Since the vertical cracks in the middle of the gable were mainly related to horizontal bending and the horizontal ones to vertical bending, the models somehow overestimated the constraint provided to the vertical sides of the façade by the side walls. On the other hand, given the inversion of earthquake ground motion, running pushover analyses in both directions helped improving the evaluation of the out-of-plane behaviour of the wall, since both the stress state in the side walls and the constraint they provide to the façade resulted to be affected by the direction of the applied loads.

FE pushover analyses provided a maximum resultant base shear $\mathrm{V}=1.25 \mathrm{~W}$ (macro-modelling) and $\mathrm{V}=1.75 \mathrm{~W}$ (micro-modelling) for the Brick House (Table 3), and $\mathrm{V}=1.55 \mathrm{~W}$ (macro-modelling) and $\mathrm{V}=0.73 \mathrm{~W}$ (micromodelling) for the Stone House (Table 4), W being the self-weight of the structure. Nevertheless, the outcomes for macro-modelling were sensitive to the mesh size (not for refined discretizations) and to the constitutive cracking relationship assumed (shear retention). The displacement demand was estimated with non-linear time history analyses, carried out under the signal recorded on the shake table. The displacements simulated by the FE models resulted one order of magnitude smaller than the experimental ones $(18 \mathrm{~mm}$ and $16 \mathrm{~mm}$ at the maximum for brick and stone specimen, respectively, Figures $4 \mathrm{~b}, \mathrm{~d})$. As said before, this could be attributed to the difficulty of simulating the large displacements exhibited by cracked structures immediately before collapsing (Figures $2 \mathrm{~b}, \mathrm{~d}$ and 9 ).

A micro-modelling approach with 3D finite elements was also used in (Gams et al., 2016). The model of the Brick House reproduced the arrangement of the units in the plane of the wall, while that of the Stone House made use of parallelepiped units roughly corresponding to the average size of the stones. In both cases, the walls were assumed as made out of one leaf only, and perfect connection was assumed between all the elements to simplify model generation. Again, units were elastic and non-linearities were concentrated in the mortar, but the joints were modelled with 3D elements rather than by zero-thickness interfaces. The limited tensile and compressive strengths of the mortar were calibrated based on the results of diagonal and vertical compression tests, respectively, while no shear failure was included. This refined model was used to run pushover analyses in direction normal to the façade (both inwards and outwards) and to identify the failure mechanism. A good agreement was found with the crack pattern developed in shake table tests in the side walls, but not in the front wall, where cracks are foreseen only in the centre of the gable and not in the lower part of the façade (Figure 5d and 7d). A simplified model, computationally more efficient than the former one, was used to run non-linear dynamic analyses with time-step integration under the recorded acceleration time histories. 3D linear elastic finite elements were used separated by frictional interfaces (with zero cohesion) placed where cracks developed in the last tests on the shake table. The friction coefficient of the contact surfaces and the viscous damping were calibrated to match as much as possible the experimental response, and resulted to be 0.6 and $0 \%$, respectively, for both the Brick House and the Stone House. Nevertheless, in the former, the displacement response resulted highly overestimated, since the dynamic analyses diverged (making the displacement demand undetectable, Figure 9a). In the latter, only a partial 
agreement was achieved, due to the occurrence in shake table tests of several cracks that changed the mechanism, and the estimated seismic demand was 130 $\mathrm{mm}$ (Figure 9b).

\subsection{Discrete element method}

Two different Discrete Element modelling approaches were developed, with either macro-elements or distinct elements. Even if the formulations adopted are rather different, both approaches describe the cracked structure as an assembly of rigid blocks (allowed to rotate and slide) separated by contact interfaces, to simulate crack development and identify the failure mechanism. The macro-element approach developed in (Cannizzaro and Lourenço, 2016), makes use of quadrilateral elements connected by interfaces provided with discrete non-linear springs. The model is able to reproduce the in-plane and the out-of-plane behaviour of masonry walls with limited computational effort. Two models were built, one with elements larger than the bricks/stones, and another one whose elements had the same size of the bricks or comparable to that of the stones. Obviously, the latter (having some analogies with the micro-modelling FE schemes described beforehand) offered a better detail (also including the orthotropy of the masonry due to the actual brick/stone arrangement), at higher computational costs than the former.

Pushover analyses under mass proportional loads were carried out, in the inwards and in the outwards directions. The models with refined reproduction of bricks/stones texture led to a better agreement with experimental result, when compared to the simplified arrangement. The failure mechanisms were also reasonably well simulated, especially for what concerns the in-plane crack pattern in the side walls, the damage developed in the lower part of the front wall, and the torsional response. Some inconsistencies were found at the top of the façade, with the damage in the middle of the gable being overestimated (Figures 5e and 7e). The displacement demand was not evaluated, while the seismic capacity was measured in terms of base shear normalized by the self-weight (V/W) and, for the Brick House, resulted 0.85 for the DE model with larger-than-real units and 1.0 for the model built with units as large as the bricks (Table 3 ), and for the Stone House 1.3 and 1.4, respectively (Table 4).

A 3D Distinct Element model was developed in (Lemos and Campos Costa, 2016) to simulate the seismic behaviour of the Stone House only. The model comprised rigid blocks separated by Mohr-Coulomb joints, with limited tensile and shear strength, and constant friction angle. In order to reduce modelling complexity and runtime, the actual morphology of the stone masonry was not reproduced in detail, since a single leaf of stone units with continuous bed joints was assumed. The solution algorithm is explicit, as equilibrium is written for each block in the time domain and static solutions are found by overdamping the system and/or by applying loads (e.g., the self-weight) with small consecutive increments. Explicit schemes require very small time steps to get stable solutions, requiring long runtime for models with many units. To overcome this limitation, the blocks used in this combined finite-discrete model were larger than real bricks or stones.

A similar model was used to predict the shake table tests before the outcome were unveiled. Within the simulation a posteriori some parameters were updated to match experimental results. First, the stiffness of the joints was reduced by $50 \%$, and the friction angle was increased from $30^{\circ}$ to $35^{\circ}$ (a way to take into account an actual arrangement of the stones more irregular than the numerical model). Second, the boundary conditions at the base of the model were changed from rigid to elastic, to reproduce the movements of the shake table, the stiffness of these new contacts being tuned by trial and error to match experimental mode shapes and frequencies. Third, the Rayleigh damping was recalibrated to match the results of the final test (the most severe one), and a value of $2 \%$ at $10 \mathrm{~Hz}$ frequency was set ( $1 \%$ at $1 \mathrm{~Hz}$ was used in the predictions). Finally, the acceleration time history actually recorded on the shake table was used for postdictions, as it was not available for the predictions. The improved resemblance with experimental results highlighted the sensitivity of the model to the input variables. After the re-calibration, the numerical model was able to capture natural frequencies and modal shapes, to provide a displacement response close to experimental measurements not only at collapse but also under earthquake base motions with lower intensity (Figure 9b), and to approximately reproduce the failure mode (Figure $7 \mathrm{f}$ and Figure 8, mechanism \#5). This latter was obtained by pushover analyses under mass proportional loads, and by non-linear dynamic analyses, and resulted similar to that foreseen in the prediction (mechanism \#9, see Mendes et al., 2016). It should be noted that, being the actual failure mechanism dependent on the arrangement of the units, a close agreement with DEM predictions was not expected, due to the simplified geometry assumed in the model. In fact, the numerical model provided more distributed damage and was not able to reproduce progressive damage accumulation. 


\subsection{Combined finite-discrete element methods}

A combined finite-discrete element method was used by AlShawa et al. (2016). The masonry specimens were modelled as an assembly of discrete 3D units, separated by interfaces. Differently from the DE models described previously, the units were meshed with finite elements. Units were assumed to be linear, elastic and isotropic, while interfaces were provided with limited tensile and shear strength, and represented the surfaces where crack can form, and separation and re-contact can occur. Again, this approach offered the possibility of reproducing the discontinuous nature of masonry. Also, it allowed to account for the deformation of the blocks that is neglected in the DEM model used in (Lemos and Campos Costa, 2016). This approach adopts again an explicit solution for the equation of motion, as in the DEM, requiring small steps and a relatively low number of blocks. This same combined FEM/DEM approach was used to identify the failure mechanism in the blind predictions. To perform postdictions, some variables (namely, the contact stiffness, and the normal and shear failure limit stress) were re-calibrated a posteriori to match experimental results. The method provided a good representation of the collapse mechanisms (Figures $5 \mathrm{f}$ and $7 \mathrm{~g}$ ) and of the displacement demand at (or near) collapse for both the Brick House (Figures $4 \mathrm{~b}$ and $9 \mathrm{a}$ ) and the Stone House (Figure $4 \mathrm{~d}$ and $9 \mathrm{~b}$ ). The seismic demand, but not the collapse mechanism, was found to be highly sensitive to the tensile strength of the interfaces, which is impossible to determine in real situations. 
Table 3. Postdictions for the Brick House.

\begin{tabular}{|c|c|c|c|c|c|c|}
\hline Participant & Mechanism $^{(1)}$ & $\mathrm{D}[\mathrm{mm}]$ & $\mathrm{V} / \mathrm{W}[-]$ & $\begin{array}{l}\text { Modelling } \\
\text { approach }\end{array}$ & $\begin{array}{c}\text { Analysis } \\
\text { method }\end{array}$ & Notes \\
\hline \multicolumn{2}{|l|}{ Experimental } & 136 & & & & \\
\hline $\begin{array}{l}\text { I } \\
\text { (Derakhshan } \\
\text { et al., 2016) }\end{array}$ & 1 & 510 & & $\mathrm{RB}$ & $\begin{array}{l}\mathrm{S} \text { (non- } \\
\text { linear) }\end{array}$ & $\begin{array}{l}\text { Failure mode not simulated. Assessment } \\
\text { performed starting from the mechanism } \\
\text { observed in shake table tests. Displacement } \\
\text { demand overestimated at low input intensity } \\
\text { (far from rocking activation). }\end{array}$ \\
\hline $\begin{array}{l}\text { II } \\
\text { (AlShawa et } \\
\text { al., 2016) }\end{array}$ & 2 & 105 & & FEM/DEM & IDA & $\begin{array}{l}\text { Strength parameters of the model re-calibrated. } \\
\text { Block discretization refined. Assessment results } \\
\text { are highly sensitive to the tensile strength } \\
\text { assumed for contact interfaces. Therefore, no } \\
\text { seismic capacity is estimated and the use of } \\
\text { limit analysis based approaches with equivalent } \\
\text { rigid block systems is suggested on the } \\
\text { mechanism predicted by FEM. }\end{array}$ \\
\hline \multirow{2}{*}{$\begin{array}{l}\text { III } \\
\text { (Gams et al., } \\
\text { 2016) }\end{array}$} & 3 & - & & FEM-micro & POA & $\begin{array}{l}\text { Two way (inwards/outwards) analysis carried } \\
\text { out to simulate the failure mechanism. Results } \\
\text { satisfactory for the in-plane damage of the side } \\
\text { walls but not for the out-of-plane damage of the } \\
\text { facade. }\end{array}$ \\
\hline & Exp & Diverg. & & FEM-meso & IDA & $\begin{array}{l}\text { Simplified model with elastic elements and } \\
\text { contact surfaces to represent the failure } \\
\text { mechanism observed in shake table tests. } \\
\text { Dynamic analyses diverged, so the seismic } \\
\text { demand resulted overestimated by the model. }\end{array}$ \\
\hline \multirow{2}{*}{$\begin{array}{c}\text { IV } \\
\text { (Cannizzaro } \\
\text { and Lourenço, } \\
\text { 2016) }\end{array}$} & 3 & & $0.85^{(2)}$ & $\operatorname{DEM}^{(\mathrm{A})}$ & POA & \multirow{2}{*}{$\begin{array}{l}\text { (A) Elements larger than bricks / }{ }^{(B)} \text { of the same } \\
\text { size of bricks. } \\
\text { Two way (inwards/outwards) analysis carried } \\
\text { out to simulate the failure mechanism. Results } \\
\text { satisfactory especially for the model with } \\
\text { elements as large as the bricks and for the in- } \\
\text { plane damage of the side walls, but not } \\
\text { completely satisfactory for the out-of-plane } \\
\text { damage of the façade. }\end{array}$} \\
\hline & 6 & & $1.0^{(2)}$ & $\mathrm{DEM}^{(\mathrm{B})}$ & POA & \\
\hline \multirow{4}{*}{$\begin{array}{l}\text { V } \\
\text { (Chácara et } \\
\text { al., 2016) }\end{array}$} & 3 & & $1.25^{(2)}$ & FEM-macro & POA & \multirow{2}{*}{$\begin{array}{l}\text { Two way (inwards/outwards) analysis carried } \\
\text { out to simulate the failure mechanism. Results } \\
\text { satisfactory for the in-plane damage of the side } \\
\text { walls, but not for the out-of-plane damage of } \\
\text { the façade. }\end{array}$} \\
\hline & 4 & & $1.75^{(2)}$ & FEM-micro & POA & \\
\hline & 3 & 18 & & FEM-macro & IDA & \multirow{2}{*}{$\begin{array}{l}\text { Failure mechanism correctly replicated, } \\
\text { especially on the side walls and by the micro- } \\
\text { modelling approach. Displacement demand } \\
\text { underestimated. }\end{array}$} \\
\hline & 5 & 5 & & FEM-micro & IDA & \\
\hline
\end{tabular}

D: seismic displacement demand; V/W: maximum base shear (normalized by the self-weight) attained in pushover analyses; RB: limit analysis with rigid-body systems; FEM -micro/-meso/-macro: Finite Elements Method with micro-/meso-/macro- modelling approaches; DEM: Distinct Element Method; POA: pushover analysis; IDA: incremental dynamic analysis (time-step integration under earthquake base motion).

(1) See Figure 6.

(2) Referred to the weakest direction (inwards/outwards). 
Table 4. Postdictions for the Stone House.

\begin{tabular}{|c|c|c|c|c|c|c|}
\hline Participant & Mechanism $^{(1)}$ & $\mathrm{D}[\mathrm{mm}]$ & $\mathrm{V} / \mathrm{W}[-]$ & $\begin{array}{l}\text { Modelling } \\
\text { approach }\end{array}$ & $\begin{array}{c}\text { Analysis } \\
\text { method }\end{array}$ & Notes \\
\hline \multicolumn{2}{|c|}{ Experimental } & \multicolumn{5}{|l|}{219} \\
\hline $\begin{array}{l}\text { I } \\
\text { (Derakhshan et } \\
\text { al., 2016) }\end{array}$ & 1 & 208 & & $\mathrm{RB}$ & $\begin{array}{l}\mathrm{S} \text { (non- } \\
\text { linear) }\end{array}$ & $\begin{array}{l}\text { Failure mode not simulated. Assessment } \\
\text { performed starting from the mechanism observed } \\
\text { in shake table tests. Displacement demand } \\
\text { overestimated at low input intensity (far from } \\
\text { rocking activation). }\end{array}$ \\
\hline $\begin{array}{l}\text { II } \\
\text { (AlShawa et al., } \\
\text { 2016) }\end{array}$ & 2 & 129 & & FEM/DEM & IDA & $\begin{array}{l}\text { Strength parameters of the model re-calibrated. } \\
\text { Block discretization refined. Assessment results } \\
\text { are highly sensitive to the tensile strength } \\
\text { assumed for contact interfaces. Therefore, no } \\
\text { seismic capacity is estimated and the use of limit } \\
\text { analysis based approaches with equivalent rigid } \\
\text { block systems is suggested on the mechanism } \\
\text { predicted by FEM. }\end{array}$ \\
\hline \multirow{2}{*}{$\begin{array}{l}\text { III } \\
\text { (Gams et al., } \\
\text { 2016) }\end{array}$} & 3 & - & & FEM-micro & POA & $\begin{array}{l}\text { Two way (inwards/outwards) analysis carried out } \\
\text { to simulate the failure mechanism. Results } \\
\text { satisfactory for the in-plane damage of the side } \\
\text { walls, but not for the out-of-plane damage of the } \\
\text { facade. }\end{array}$ \\
\hline & Exp & 130 & & FEM-meso & IDA & $\begin{array}{l}\text { Simplified model with elastic elements and } \\
\text { contact surfaces to represent the failure } \\
\text { mechanism observed in shake table tests. }\end{array}$ \\
\hline \multirow[b]{2}{*}{$\begin{array}{c}\text { IV } \\
\text { (Cannizzaro and } \\
\text { Lourenço, 2016) }\end{array}$} & 4 & & $1.3^{(2)}$ & $\operatorname{DEM}^{(\mathrm{A})}$ & POA & \multirow{2}{*}{$\begin{array}{l}\text { (A) Elements larger than stones / }{ }^{(B)} \text { of similar size } \\
\text { of stones. } \\
\text { Two way (inwards/outwards) analysis carried out } \\
\text { to simulate the failure mechanism. Results } \\
\text { satisfactory especially for the model with } \\
\text { elements as large as the bricks and for the in- } \\
\text { plane damage of the side walls, but not } \\
\text { completely satisfactory for the out-of-plane } \\
\text { damage of the façade. }\end{array}$} \\
\hline & 6 & & $1.4^{(2)}$ & $\operatorname{DEM}^{(\mathrm{B})}$ & POA & \\
\hline \multirow{4}{*}{$\begin{array}{l}\text { V } \\
\text { (Chácara et al., } \\
\text { 2016) }\end{array}$} & 3 & & $1.55^{(2)}$ & $\begin{array}{l}\text { FEM- } \\
\text { macro }\end{array}$ & POA & \multirow{2}{*}{$\begin{array}{l}\text { Two way (inwards/outwards) analysis carried out } \\
\text { to simulate the failure mechanism. Results } \\
\text { satisfactory for the in-plane damage of the side } \\
\text { walls, but not for the out-of-plane damage of the } \\
\text { façade. }\end{array}$} \\
\hline & 3 & & $0.73^{(2)}$ & FEM-micro & POA & \\
\hline & 3 & 12 & & $\begin{array}{l}\text { FEM- } \\
\text { macro }\end{array}$ & IDA & \multirow{2}{*}{$\begin{array}{l}\text { Failure mechanism correctly replicated, } \\
\text { especially on the side walls and by the micro- } \\
\text { modelling approach. Displacement demand } \\
\text { underestimated. }\end{array}$} \\
\hline & 4 & 16 & & FEM-micro & IDA & \\
\hline $\begin{array}{c}\text { VI } \\
\text { (Lemos and } \\
\text { Campos Costa, } \\
\text { 2016) }\end{array}$ & 5 & 130 & & DEM & IDA & $\begin{array}{l}\text { Failure mode in good agreement with the } \\
\text { experimental mechanism. Displacements } \\
\text { provided by dynamic analyses agree with } \\
\text { experimental measurements for all the tests of the } \\
\text { shake table session. }\end{array}$ \\
\hline
\end{tabular}

D: seismic displacement demand; V/W: maximum base shear (normalized by the self-weight) attained in pushover analyses; RB: limit analysis with rigid-body systems; FEM -micro/-meso/-macro: Finite Elements Method with micro-/meso-/macro- modelling approaches; DEM: Distinct Element Method; POA: pushover analysis; IDA: incremental dynamic analysis (time-step integration under earthquake base motion).

(1) See Figure 8 .

(2) Referred to the weakest direction (inwards/outwards). 

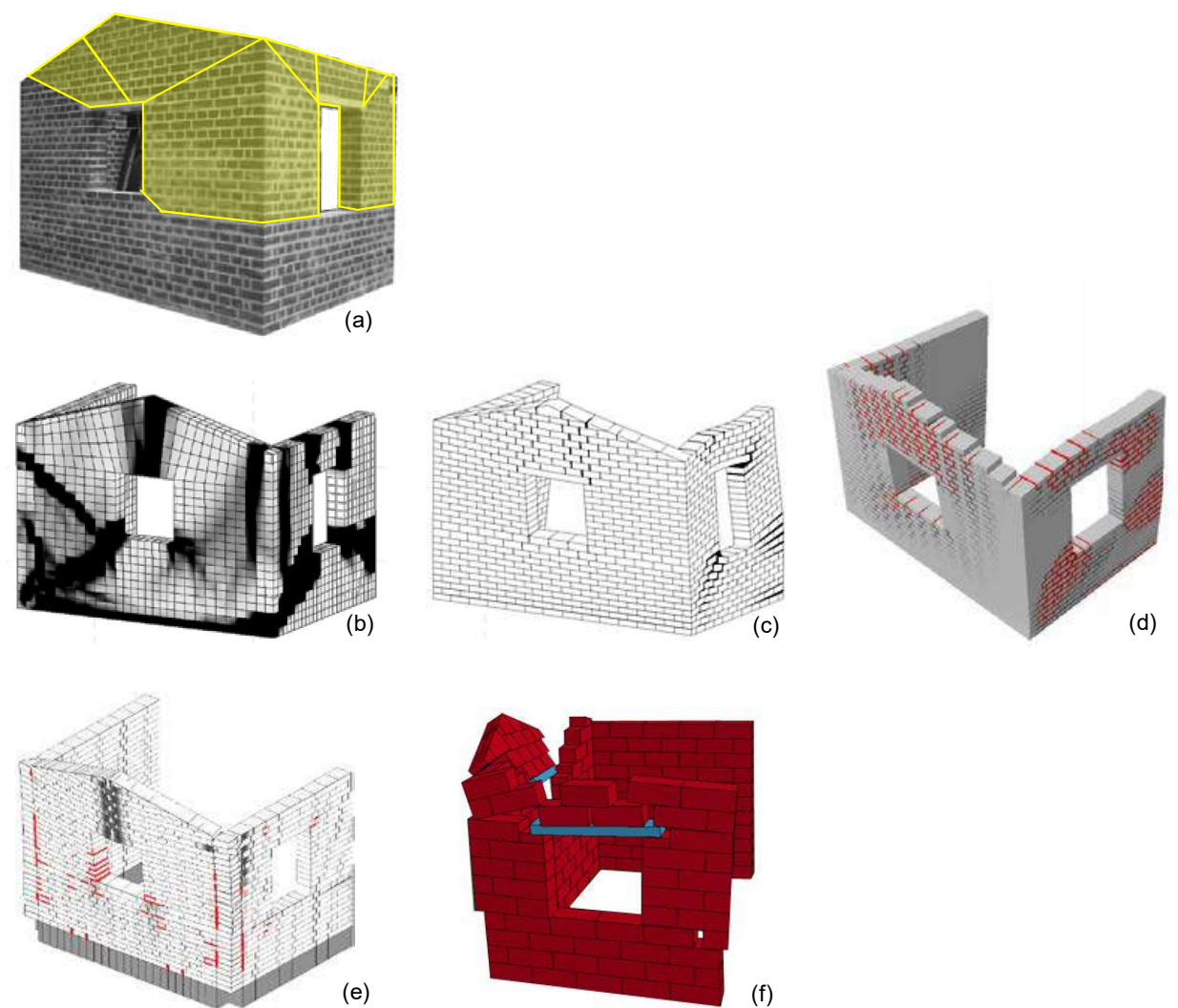

Figure 5. Failure mechanism of the Brick House: experimental outcome (a) and simulations with macro-FEM (b), micro-FEM (c,d), discrete macro-elements (e), and combined finite-discrete elements (f).
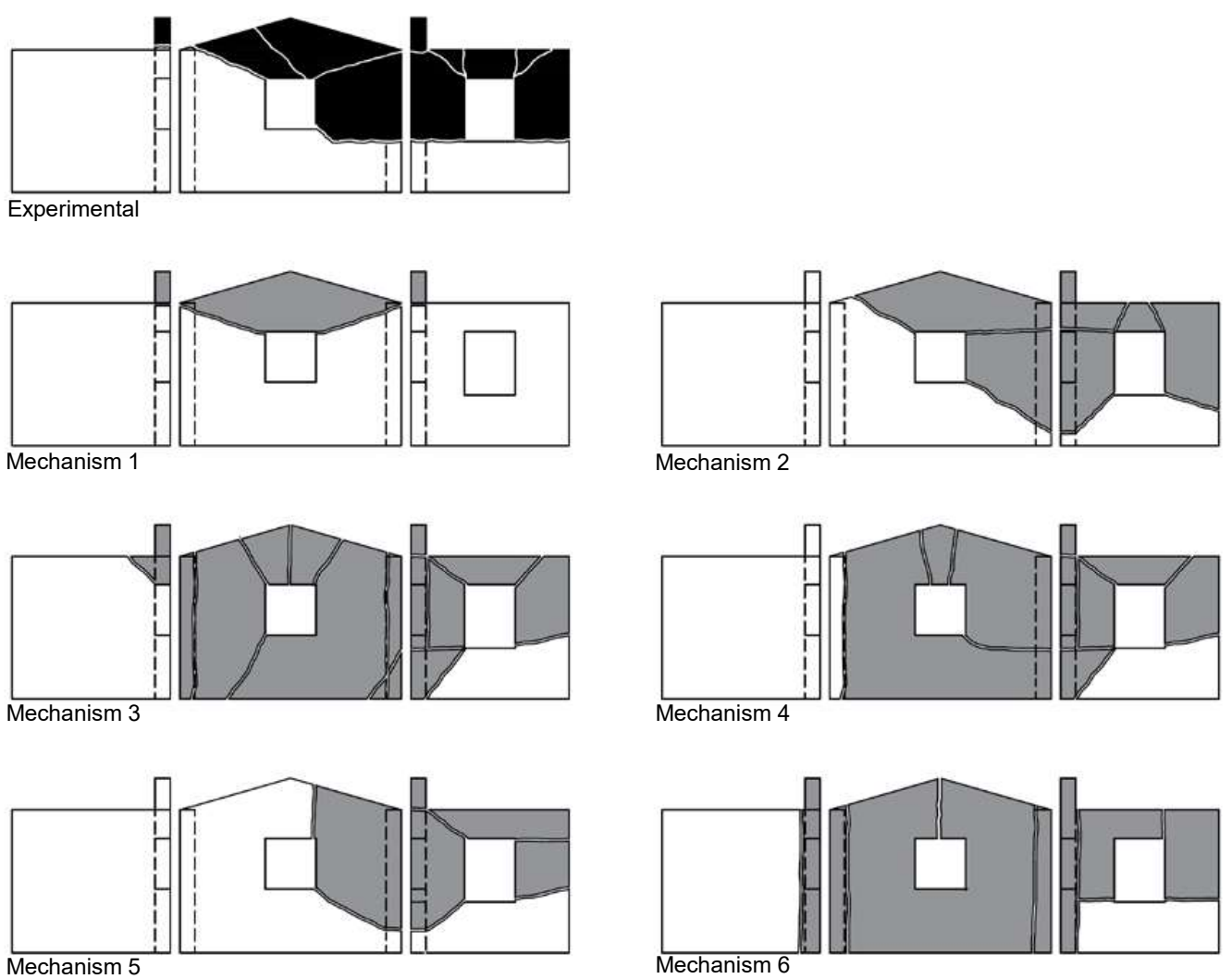

Figure 6. Experimental mechanism and mechanisms assumed (\#1) and simulated (\#2-6) in postdictions for the Brick House. 

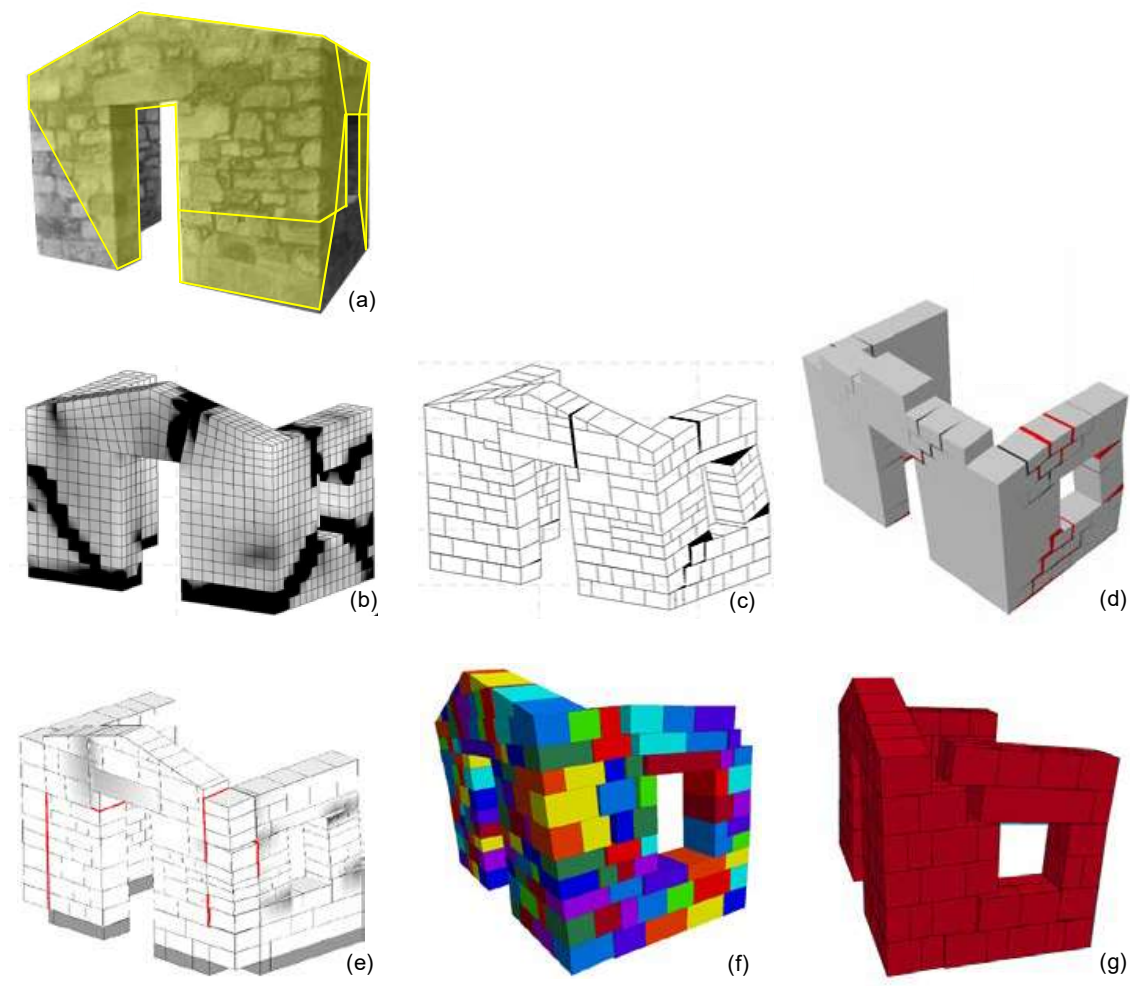

Figure 7. Failure mechanism of the Stone House: experimental outcome (a) and simulations with macro-FEM (b), micro-FEM (c,d), discrete macro-elements (e), Distinct Elements (f), and combined finite-discrete elements (g).
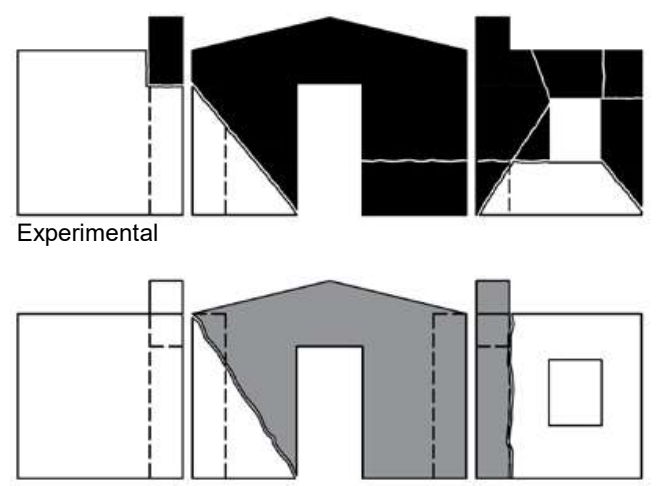

Mechanism 1

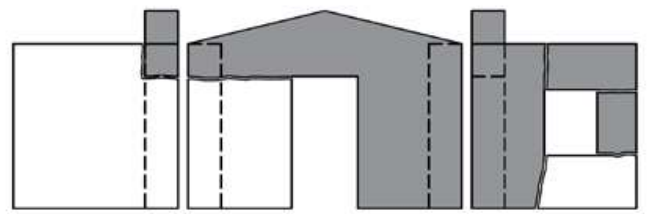

Mechanism 2

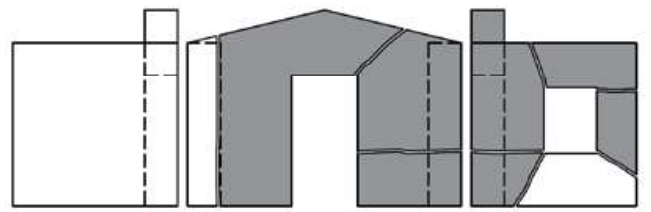

Mechanism 3

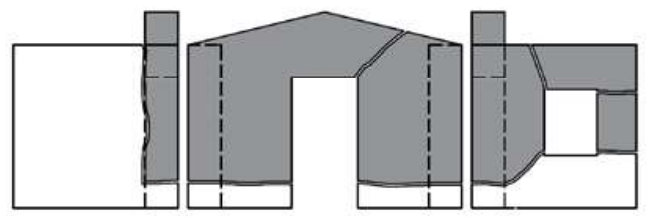

Mechanism 4

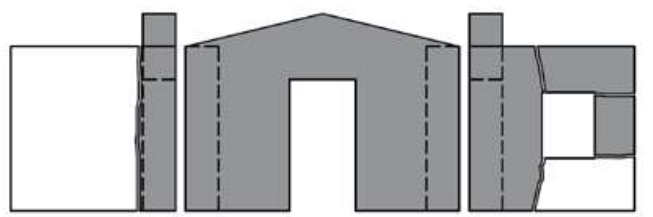

Mechanism 5

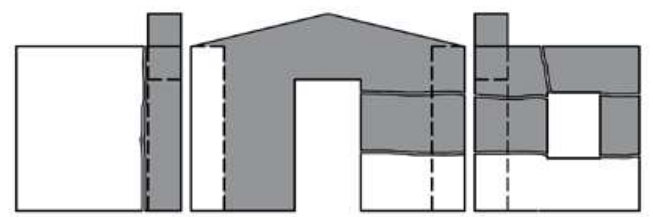

Mechanism 6

Figure 8. Experimental mechanism and mechanisms assumed (\#1) and simulated (\#2-6) in postdictions for the Stone House. 

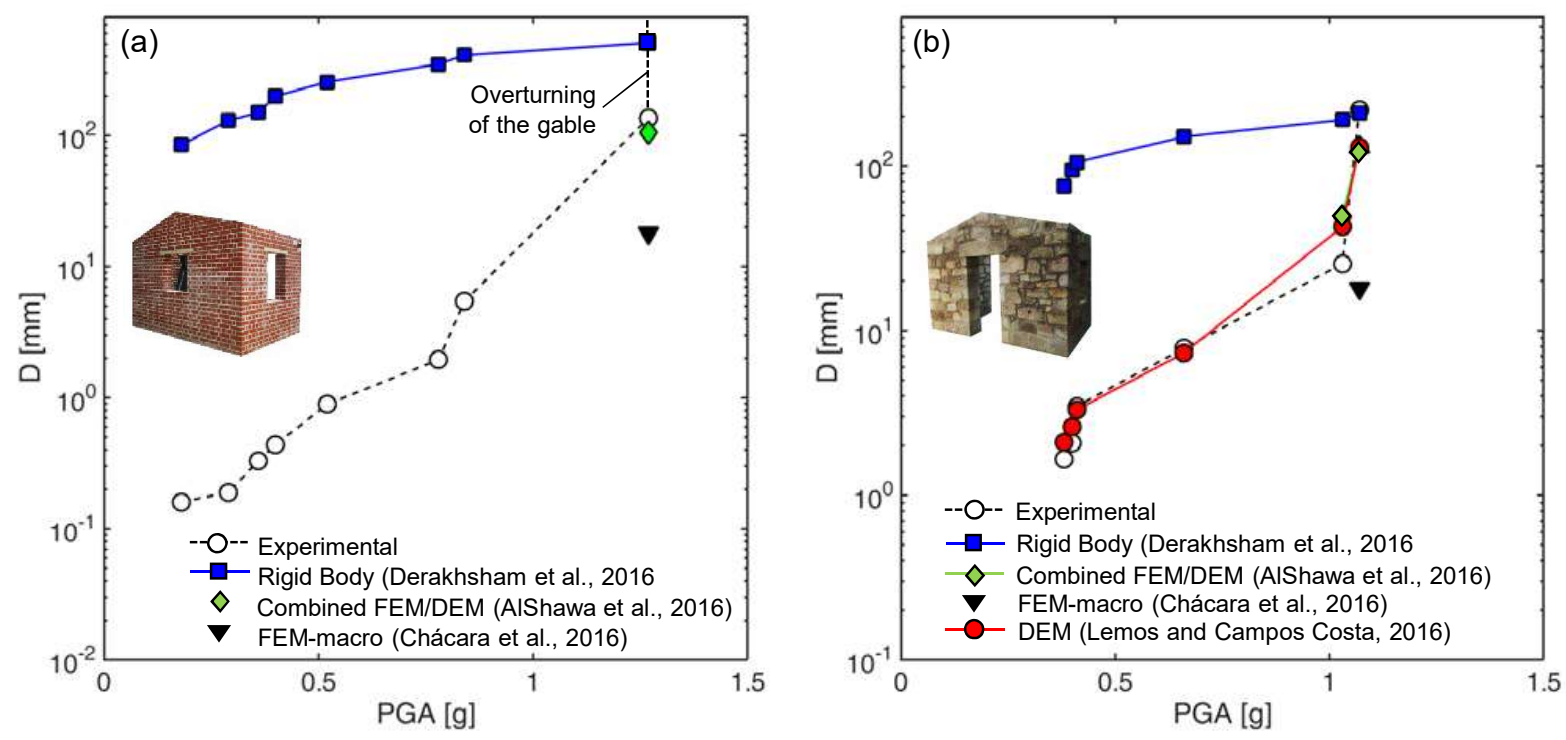

Figure 9. Comparison between experimental displacements and displacement demand estimated by postdictions for the Brick House (a) and for the Stone House (b).

\section{DISCUSSION AND CONCLUDING REMARKS}

Aiming at understanding the benefits and limitations of the methods currently available for the seismic assessment of existing masonry structures, an initiative was carried out, including (i) shake table tests on two large-scale specimens, one built with clay brick masonry and one with stone masonry (Candeias et al., 2016), (ii) blind test predictions (Mendes et al., 2016) and (iii) simulations a posteriori of experimental results, making use of different modelling strategies.

Shake table tests confirmed that, in the specimens under investigation, the dynamic behaviour, the collapse mechanism, and, consequently, the seismic capacity were influenced by the effective connections between the side walls the façade, which prevented the out-of-plane overturning of the latter as a nearly rigid body whilst promoting a bending failure. The opening in the front wall constituted a weak element and that in the side wall produced a strong torsional behaviour (Candeias et al., 2016). The incidence of these features in the response of existing masonry structures to earthquake proves, on the one hand, that it is worth investing in large-scale dynamic testing and, on the other hand, the importance of an accurate survey of geometry and construction details, as the first step of the seismic assessment in engineering applications. Despite of the information that can be derived from shake table tests, it must be noted that they differ by their very nature from real situations, since: (i) one or few selected signals are used as input, but the structural dynamic response is highly sensitive to the characteristics of the ground motion; (ii) several tests are usually performed with the input(s) that are progressively scaled up, and the identification of a single input equivalent to the whole sequence is hardly possible; (iii) the structural model built in the laboratory, even in the full scale, can differ from real structures; and (iv) the repeatability of test outcomes may be compromised by the variability of the complex phenomena under investigation. Some of these limitations (sensitivity to the input, identification of a single accelerograms, or of a synthetic intensity measure, equivalent to the whole session) deserve more research. To this purpose, considering the complexity and cost of shake table tests, extensive numerical analyses on refined models calibrated on shake table test results could contribute gaining a deeper understanding.

The blind test prediction of the out-of-plane seismic capacity resulted extremely challenging, especially for the brickwork specimen, due to its higher flexibility with respect to the one built in stone masonry (Mendes et al., 2016). Predictions of the failure mechanism displayed a large variability, mainly depending on the assumptions on: (i) the effectiveness of the connections between front and side walls; (ii) the bending strength of the façade; and (iii) the in-plane strength of side walls. A method to achieve good estimates appears unavailable, whilst a combination of numerical discrete models and engineering judgement seems able to provide the best guess of the failure mode. Estimates of capacity also differed largely, with Coefficients of Variation being about $40-60 \%$, with a significant underestimation of the actual capacity, 
especially for the Brick House $(-51 \%)$ when compared to the Stone Housed $(-15 \%)$, even when the correct failure mechanism was assumed.

Postdictions were carried out with different approaches, ranging from analytical methods based on rigidbody mechanisms to numerical models. The former ones allow for a faster assessment and the results depend on a limited number of variables, possibly more easily controlled and this is a reason to make them recommended in a few codes (Sorrentino et al., 2016). Still, the definition of simplified models is not errorproof and may lead to wrong estimates, requiring experience and engineering judgment. Due to their complexity and longer time needed for model generation and analysis, most of the refined computational methods are mainly used for research and have not been extensively transferred to engineering practice.

Clearly, since the experimental results were known at this stage, a better agreement was found between postdictions and experimental results than in blind predictions. Still, much information was derived on the potentialities and the limitations of the various approaches adopted. In some cases, the failure mechanism was assumed as the starting point of the assessment. Alternatively, the capability of the model to estimate both the failure mechanism and the seismic displacement demand was investigated.

Once the mechanism is correctly identified, a limit analysis based approach is the fastest way to estimate the seismic capacity. Nevertheless, the static solution of this problem does not account for size effects, thus being often over-conservative. Furthermore, the schematization of a real failure mode with a mechanism presents by itself non-negligible difficulties, related to the identification of the blocks of the system and to the definition of the boundary conditions (Giresini et al., 2015). Rigid-block analysis is also affected by the uncertainties related to the crushing strength of masonry and to the consequent exact position of the hinges. The development of assessment methods based on multi-block dynamics, that appropriately model (e.g., by springs) the interaction among blocks and the boundary conditions appears particularly promising. Finally, the assessment via response spectrum is affected by the uncertain evaluation of the period and of the damping of the equivalent single-degree-of-freedom system. Recent studies have proposed a dynamic approach that represents multi-block mechanism with equivalent rocking models, characterized by fundamental rocking parameters (DeJong and Dimitrakopoulos, 2014). By doing so, the dynamic behaviour of rocking structures can be assessed analytically under pulse base input (Mauro et al., 2015) or by numerical integration of the equations of motion under earthquake base excitation.

As an alternative to limit analysis based approaches, finite elements, distinct elements, and combined finite/distinct elements can be used. The capability of these approaches to estimate the correct mechanism and the seismic displacement demand was investigated, as well as the sensitivity of the results to aspects such as meshing, strength properties, analysis parameters, and input characteristics. The experts that run predictions and postdictions had the possibility to update their models by re-calibrating parameters to match experimental results, highlighting the sensitivity of the assessment approaches to the input.

Finite Elements were used with macro-, meso- or micro-modelling approaches. Clearly, the better detail required a higher computational effort. FEM models caught the torsional response of the asymmetric structure and provided a good simulation of the damage developed in side walls (loaded in-plane). On the other hand, despite pushover analyses performed in both directions (inwards and outwards) helped improving the evaluation of the out-of-plane behaviour of the wall, the collapse mechanism activated on the façade (loaded out-of-plane) was not clearly simulated. The analyses carried out suggest that the continuum nature in FE macro-modelling may compromise the reliability of the results, when cracked blocky structures experiencing large rigid body displacements/rotations near collapse.

A better representation can be achieved by modelling the possible occurrence of cracks with surfaces of discontinuity. Discrete modelling can be performed by recurring to the Distinct Element Method, to macroelements, to combined Finite/Discrete elements or to FEM micro-models. DEM proved to be particularly useful to predict the collapse mechanism and to provide a good description of the dynamics of masonry structures. The explicit integration algorithm of DEM provides numerical stability but a sufficiently small time step is necessary, making the runtime extremely long for 3D models with many blocks. The sensitivity to parameters such as input and damping, and the extremely high computational efforts required for model generation and analysis preclude, at this stage, an extensive use of discrete models for engineering practice purposes, limiting its applications to the research. More research seems needed in a better representation of joint properties (e.g., by hysteretic dissipation and strength degradation) to simulate progressive damage accumulation, and of damping, which is hardly definable as one single global parameter of the structure. The tools available for researchers and practitioners may significantly contribute to the estimate of seismic safety of existing masonry structures, but appear by themselves not yet sufficient for a refined prediction of the failure mechanism and a reliable estimate of the seismic displacement demand. This suggests that guidelines should provide practitioners with sufficiently conservative safety factors and that engineering 
judgement and information from past earthquakes should be associated to structural analysis for assessment and rehabilitation design purposes, as recommended in international guidelines, ICOMOS/ISCARSAH Guidelines (2005). Due to some sensitivity of FEM and DEM to aspects such as mesh refinement, material characteristics, boundary conditions, damping, and input properties, preliminary sensitivity analyses or probabilistic approaches are possibly needed to assess the robustness of the outcomes of numerical simulations. The studies carried out within this research indicated that a proper tuning of some input variables significantly improves the agreement with experimental results, particularly in terms of failure mode and displacement demand. Therefore, investments on dynamic identification and monitoring and welldesigned destructive field testing in engineering applications are essential, as they allow calibrating the numerical models and increasing the reliability of structural analysis.

\section{REFERENCES}

AlShawa, O., de Felice, G., Mauro, A., and Sorrentino, L. 2012. Out-of-plane seismic behaviour of rocking masonry walls. Earthq. Eng. Struct. Dyn., 41(5):949-968.

AlShawa, O., Sorrentino, L., and Liberatore, D. 2016. Simulation of shake table results on out-of-plane masonry buildings. Part (II): Combined finite-discrete elements. Int. J. Archit. Herit., This issue.

Benedetti, D., Carydis, P., and Pezzoli, P. 1998. Shaking table tests on 24 simple masonry buildings. Earthq. Eng. Struct. Dyn., 27(1):67-90.

Bothara, J.K., Dhakal, R.P., and Mander, J.B. 2010. Seismic performance of an unreinforced masonry building: An experimental investigation. Earthq. Eng. Struct. Dyn., 39(1):45-68.

Candeias, P.X, Campos Costa, A., Mendes, N., Costa, A.A., and Lourenço, P.B. 2016. Experimental assessment of the out of plane performance of masonry buildings through shake table tests. Int. J. Archit. Herit., This issue.

Cannizzaro, F., and Lourenço, P.B. 2016. Simulation of shake table results on out-of-plane masonry buildings. Part (VI): Discrete element approach. Int. J. Archit. Herit., This issue.

Chácara, C., Mendes, N., and Lourenço, P.B. 2016. Simulation of shake table results on out-of-plane masonry buildings. Part (IV): Macro and micro FEM based approaches. Int. J. Archit. Herit., This issue.

Costa, A.A., Arêde, A., Campos Costa, A., Penna, A. and Costa, A. 2013. Out-of-plane behaviour of a full scale stone masonry façade. Part 2: shaking table tests. Earthq. Eng. Struct. Dyn., 42(14):2097-2111.

De Canio, G., de Felice, G., De Santis, S., Giocoli, A., Mongelli, M., Paolacci, F., and Roselli, I. 2016. Passive 3D motion optical data in shaking table tests of a SRG-reinforced masonry wall. Earthq. Struct., 10(1):53-71.

de Felice, G. 2011. Out-of-plane seismic capacity of masonry depending on wall section morphology. Int. J. Archit. Herit., 5(45):466-482.

De Santis, S., Casadei, P., De Canio, G., de Felice, G., Malena, M., Mongelli, M., and Roselli, I. 2016. Seismic performance of masonry walls retrofitted with steel reinforced grout. Earthq. Eng. Struct. Dyn., 45(2):229-251.

DeJong, M.J., and Dimitrakopoulos, E.G. 2014. Dynamically equivalent rocking structures. Earthq. Eng. Struct. Dyn., 43(10):154363.

Derakhshan, H., Nakamura, Y., Ingham J.M., and Griffith, M.C. 2016. Simulation of shake table results on out-of-plane masonry buildings. Part (I): Displacement-based approach using simple failure mechanisms. Int. J. Archit. Herit., This issue.

Ferreira T.M., Costa A.A. and Costa A. 2015. Analysis of the out-of-plane seismic behaviour of unreinforced masonry: A literature review. Int. J. Archit. Herit., 9(8):949-972.

Gams, M., Anžlin, A., and Kramara M. 2016. Simulation of shake table results on out-of-plane masonry buildings. Part (III): Twostep FEM approach. Int. J. Archit. Herit., This issue.

Giresini, L., Fragiacomo, M., and Lourenço, P.B. 2015. Comparison between rocking analysis and kinematic analysis for the dynamic out-of-plane behavior of masonry walls. Earthq. Eng. Struct. Dyn., 44(13):2359-2376.

ICOMOS/ISCARSAH Guidelines 2005. Recommendations for the anal ysis, conservation and structural restoration of architectural heritage.

Lemos, J.V., and Campos Costa, A. 2016. Simulation of shake table results on out-of-plane masonry buildings. Part (V): Discrete element approach. Int. J. Archit. Herit., This issue.

Lourenço, P.B., Avila, L., Vasconcelos, G., Alves, J.P., Mendes, N., and Costa, A.C. 2013. Experimental investigation on the seismic performance of masonry buildings using shaking table testing. B. Earthq. Eng., 11(4):1157-1190.

Lourenço, P.B., Mendes, N., Ramos, L.F., and Oliveira, D.V. 2011. Analysis of masonry structures without box behaviour. Int. J. Archit. Herit., 5(4-5):369-382.

Mauro, A., de Felice, G., and DeJong, M. 2015. The relative dynamic resilience of masonry collapse mechanisms. Eng. Struct., 85:182-194.

Mendes, N., and Lourenço, P.B. 2010. Seismic assessment of masonry Gaioleiro buildings in Lisbon, Portugal. J. Earthq. Eng., 14(1):80-101.

Mendes, N., and Lourenço, P.B. 2014. Sensitivity analysis of the seismic performance of existing masonry buildings Eng. Struct., 80:137-146.

Mendes, N., Costa' A.A., Lourenço' P.B., Bento, R., Beyer, K., de Felice, G., Gams, M., Griffith, M., Ingham, J., Lagomarsino, S., Lemos, J.V.. Liberatore, D., Modena, C., Oliveira, D.V., Penna, A., and Sorrentino, L. 2016. Methods and approaches for blind test predictions of out-of-plane behavior of masonry walls: an experimental comparative study. Int. J. Archit. Herit., This issue.

Mendes, N., Lourenço, P.B., and Campos-Costa, A. 2014. Shaking table testing of an existing masonry building: Assessment and improvement of the seismic performance. Earthq. Eng. Struct. Dyn., 43(2):247-266. 
Sorrentino, L., D’Ayala, D., de Felice, G., Griffith, M., Lagomarsino, S., and Magenes, G. 2016. Review of out-of-plane seismic assessment techniques applied to existing masonry buildings. Int. J. Archit. Herit., this issue.

Sorrentino, L., Masiani, R., and Decanini, L.D. 2006. Overturning of rocking rigid bodies under transient ground motions. Struct. Eng. Mech., 22(3):293-310. 